\title{
ApoE4 Alters ABCA1 Membrane Trafficking in Astrocytes
}

\author{
Varun Rawat, ${ }^{1 *}$ Shaowei Wang, ${ }^{1 *}$ Jian Sima, ${ }^{1}$ Roni Bar, ${ }^{2}$ Ori Liraz, ${ }^{2}$ Usha Gundimeda, ${ }^{1}$ Trusha Parekh, ${ }^{1}$ Jamie Chan, ${ }^{1}$ \\ Jan 0. Johansson, ${ }^{3}$ Chongren Tang, ${ }^{4}$ Helena C. Chui, ${ }^{1}$ Michael G. Harrington, ${ }^{5}$ Daniel M. Michaelson, ${ }^{2}$ \\ and Hussein N. Yassine ${ }^{1}$ \\ ${ }^{1}$ University of Southern California, Los Angeles, California, 90033, ${ }^{2}$ Tel Aviv University, Tel Aviv 6997801, Israel, ${ }^{3}$ Artery Therapeutics, Inc., San Ramon, \\ California 94583, ${ }^{4}$ University of Washington, Seattle, Washington 98195, and ${ }^{5}$ Huntington Medical Research Institute, Pasadena, California 91105
}

The APOE $\varepsilon 4$ allele is the strongest genetic risk factor for late-onset Alzheimer's disease (AD). ApoE protein aggregation plays a central role in $\mathrm{AD}$ pathology, including the accumulation of $\beta$-amyloid $(\mathrm{A} \beta)$. Lipid-poor ApoE4 protein is prone to aggregate and lipidating ApoE4 protects it from aggregation. The mechanisms regulating ApoE4 aggregation in vivo are surprisingly not known. ApoE lipidation is controlled by the activity of the ATP binding cassette A1 (ABCA1). ABCA1 recycling and degradation is regulated by ADP-ribosylation factor 6 (ARF6). We found that ApoE4 promoted greater expression of ARF6 compared with ApoE3, trapping ABCA1 in late-endosomes and impairing its recycling to the cell membrane. This was associated with lower ABCA1-mediated cholesterol efflux activity, a greater percentage of lipid-free ApoE particles, and lower A $\beta$ degradation capacity. Human CSF from APOE $\varepsilon 4 / \varepsilon 4$ carriers showed a lower ability to induce $\mathrm{ABCA1}$-mediated cholesterol efflux activity and greater percentage of aggregated ApoE protein compared with CSF from $A P O E$ $\varepsilon 3 / \varepsilon 3$ carriers. Enhancing ABCA1 activity rescued impaired $\mathrm{A} \beta$ degradation in ApoE4-treated cells and reduced both ApoE and ABCA1 aggregation in the hippocampus of male ApoE4-targeted replacement mice. Together, our data demonstrate that aggregated and lipidpoor ApoE4 increases $\mathrm{ABCA} 1$ aggregation and decreases $\mathrm{ABCA} 1$ cell membrane recycling. Enhancing $\mathrm{ABCA} 1$ activity to reduce $\mathrm{ApoE}$ and $\mathrm{ABCA} 1$ aggregation is a potential therapeutic strategy for the prevention of ApoE4 aggregation-driven pathology.

Key words: ABCA1; aggregation; Alzheimer's disease; ApoE; lipids

Significance Statement

ApoE protein plays a key role in the formation of amyloid plaques, a hallmark of Alzheimer's disease (AD). ApoE4 is more aggregated and hypolipidated compared with ApoE3, but whether enhancing ApoE lipidation in vivo can reverse ApoE aggregation is not known. ApoE lipidation is controlled by the activity of the ATP binding cassette A1 (ABCA1). In this study, we demonstrated that the greater propensity of lipid-poor ApoE4 to aggregate decreased ABCA1 membrane recycling and its ability to lipidate ApoE. Importantly, enhancing ABCA1 activity to lipidate ApoE reduced ApoE and ABCA1 aggregation. This work provides critical insights into the interactions among ABCA1, ApoE lipidation and aggregation, and underscores the promise of stabilizing ABCA1 activity to prevent ApoE-driven aggregation pathology.

\section{Introduction}

ApoE protein aggregation plays a central role in pathogenesis of late-onset Alzheimer's Disease (AD) by affecting ApoE's pleio-

\footnotetext{
Received June 15, 2019; revised Sept. 10, 2019; accepted 0ct. 7, 2019.

Author contributions: V.R., S.W., J.S., R.B., 0.L., T.P., U.G., J.C., and D.M.M. performed research; V.R., S.W., J.S., R.B., T.P., U.G., M.G.H., D.M.M., and H.N.Y. analyzed data; V.R. and H.N.Y. wrote the first draft of the paper; S.W., J.S., 0.L., T.P., U.G., J.O.J., C.T., H.C.C., M.G.H., D.M.M., and H.N.Y. edited the paper; J.O.J., C.T., and M.G.H. contributed unpublished reagents/analytic tools; H.N.Y. designed research; H.N.Y. wrote the paper.

Confocal microscopy was performed at the Cell and Tissue Imaging Core of the USC Research Center for Liver Diseases, which is supported by the National Institutes of Health (NIH Grant P30 DK048522). H.Y. was supported by Grants R21AG056518[SCAP], R01AG055770[scAP], and R01AG054434 from the National Institute of Aging-NIH. This work was also supported by NIH Grant P50AG05142 to H.C.C. M.G.H. was supported by the L.K. Whittier Foundation. We thank David Holtzman for the immortalized astrocytes, Alan Remaley for HeLa cells, Ashley Martinez for providing Figure 10, and Caleb Finch for critically reviewing the manuscript.

J.0.J. is founder and CEO of Artery Therapeutics, Inc. The remaining authors declare no competing interests.

*V.R. and S.W. contributed equally to this work.

Correspondence should be addressed to Hussein N. Yassine at hyassine@usc.edu.
}

tropic functions, including the accumulation of $\beta$-amyloid in the brain. Nonlipidated ApoE protein is prone to aggregation, with ApoE4 greater than ApoE3 (Hatters et al., 2006; Raulin et al., 2019), and lipidating ApoE ex vivo reduces ApoE aggregation (Hubin et al., 2019). Treatment with the nonlipidated ApoE antibody HAE-4 reduced amyloid-beta $(\mathrm{A} \beta)$ plaques in APPPS121/ApoE4 mice (Liao et al., 2018). Intracellular ApoE4 aggregates are more readily formed in the acidic endosome compartments than ApoE3 (Morrow et al., 2002). Decades before the appearance of $\mathrm{A} \beta$ fibrilization, $A P O E \varepsilon 4$ carriers have shown enlarged endosomes in the brain (Cataldo et al., 2000) containing ApoE receptors (such as ApoER2, LRP1) and the insulin receptor (Zhao et al., 2017; Prasad and Rao, 2018; Xian et al., 2018). Despite the 
broad importance of ApoE protein aggregation, mechanisms that regulate ApoE aggregation in vivo are poorly understood.

The activity of the ATP binding cassette A1 (ABCA1) is critical for ApoE lipidation and has an important role in brain amyloid plaque formation. Activating ABCA1 facilitates the transport of intracellular cholesterol from endosomes into nascent ApoE to form ApoE HDL (Vance and Hayashi, 2010). This process is dependent on ABCA1 recycling between the plasma membrane and endosomal compartments. ABCA1 recycling is controlled by the ADP-ribosylation factor 6 (ARF6). Greater expression of ARF6 traps ABCA1 in endosomes, resulting in decreased ABCA1 membrane expression and increased lysosomal degradation (Mukhamedova et al., 2016). Loss of ABCA1 activity not only increases the percentage of lipid-poor ApoE particles (Wahrle et al., 2004), but also promotes brain A $\beta$ deposition (HirschReinshagen et al., 2004; Wahrle et al., 2004; Koldamova et al., 2005). Furthermore, overexpressing ABCA1 increases the percentage of lipidated ApoE fractions and reduces $A \beta$ accumulation (Wahrle et al., 2008). In humans, genetic loss-of-function mutations in ABCA1 are associated with increased AD risk (Nordestgaard et al., 2015). CSF from participants with cognitive impairment has a lower capacity to induce cholesterol efflux via ABCA1 ex vivo (Yassine et al., 2016; Marchi et al., 2019). Therefore, understanding the factors that regulate ABCA1 activity is highly relevant to ApoE lipidation and to AD pathogenesis.

ApoE4 lipoproteins in the brain and in CSF are hypolipidated (Hu et al., 2015; Heinsinger et al., 2016; Chernick et al., 2018). In mouse brain, overexpressing ApoE4 increases the amount of smaller ApoE particles and reduces the amount of larger ApoE particles (Hu et al., 2015). In addition, ApoE4 AD mouse models have a greater percentage of lipid-poor and aggregated ApoE than their ApoE3 counterparts (Youmans et al., 2012). It is not known whether ApoE4 decreases ABCA1 activity and what the mechanisms that regulate ApoE and ABCA1 interactions are. We hypothesized that ApoE4 coaggregates with ABCA1 and decreases ABCA1 recycling. Herein, we found that ApoE4 increases ARF6 protein expression in astrocytes, resulting in the retention of ABCA1 in late endosomes as opposed to recycling endosomes. This was associated with lower ABCA1 activity, reduced ApoE lipidation, reduced $A \beta$ degradation, and greater proportions of aggregated ABCA1 and ApoE. In contrast, enhancing ABCA1 recycling to the membrane restored $A B C A 1$ activity, enhanced $\mathrm{A} \beta$ degradation, and decreased the relative amount of both aggregated ApoE4 and ABCA1. These ApoE-ABCA1 interactions are corroborated in human CSF where we found lower ABCA1mediated cholesterol efflux activity and greater aggregation of ApoE4 proteins from CSF of APOE $\varepsilon 4 / \varepsilon 4$ carriers compared with $A P O E \varepsilon 3 / \varepsilon 3$ carriers.

\section{Materials and Methods}

Clinical samples. The institutional review boards of University of Southern California (HS-16-00888) and Huntington Memorial Hospital (HMH-99-09) approved the study and all study participants gave written, informed consent. Participants were classified as non-demented based on Clinical Dementia Rating (CDR) score $=0$ as described previously (Yassine et al., 2016).

Animals. ApoE3-TR and ApoE4-TR mice were purchased from Taconic, in which the endogenous mouse ApoE was replaced by either human APOE3 or APOE4, were created by gene targeting as described previously (Sullivan et al., 1997). The mice were back-crossed to wildtype C57BL/6J mice (2BL/ 610; Harlan Laboratories) for 10 generations and were homozygous for the ApoE3 (3/3) or ApoE4 (4/4) alleles. The ApoE genotype of the mice was confirmed by PCR analysis, as described previously (Boehm-Cagan et al., 2016). All experiments were performed on age-matched male animals (4 months of age) and were approved by the Tel Aviv University Animal Care Committee. Every effort was made to reduce animal stress and to minimize animal usage. CS-6253 was kindly provided by Artery Therapeutics and was administered intraperitoneally to 2.5 months old mice for 6 weeks $(20 \mathrm{mg} / \mathrm{kg} / 48 \mathrm{~h})$. After treatment, the mice were anesthetized with ketamine and xylazine, after which they were perfused transcardially with PBS. The brains were halved for further analysis.

Cell cultures. Primary astrocytes were obtained from ApoE3 and ApoE4-TR mice pups and cultured as described previously (Simonovitch et al., 2016). Briefly, cerebral cortices from each 1-3 d-old neonatal mouse were dissected in ice-cold Hanks' Balanced Salt Solution (HBSS) (Corning, catalog \#21-021-CV), and digested with $0.25 \%$ trypsin for 20 min at 37C. Trypsinization was stopped by addition of twofold volume of DMEM (Corning, catalog \#10-013) with 10\% fetal bovine serum (FBS, Omega Scientific Inc, catalog \#FB-12) and 1\% antibiotic-antimycotic (Anti-Anti, Thermo Fisher Scientific, catalog \#15240062). The cells were dispersed into a single-cell level by repeated pipetting and filtered through $100 \mu \mathrm{m}$ cell strainers (VWR, catalog \#10199-658). After filtering, cells were centrifuged for $5 \mathrm{~min}$ at $1000 \mathrm{rpm}$ and resuspended in culture medium supplemented with $10 \%$ FBS and antibiotics. Then, cells were seeded in a $75 \mathrm{~cm}^{2}$ flask and cultured at $37^{\circ} \mathrm{C}$ in $5 \% \mathrm{CO}_{2}$. Change the medium on next day and then replace medium every $3 \mathrm{~d}$. These mixed-glia cultures reached confluence after 7-10 d. Then, cells were placed on a shaker at $250 \mathrm{rpm}$ for $16 \mathrm{~h}$ at $37^{\circ} \mathrm{C}$ to remove microglia and oligodendrocyte progenitor cells. The remaining cells were harvested by digestion with trypsin. At this stage, the culture contained 95\% astrocytes and was used for further experiments.

Immortalized mouse astrocytes derived from human ApoE3 and ApoE4 knock-in mice (Morikawa et al., 2005) were a gift from Dr. David Holtzman and grown in DMEM/F12 (Corning, catalog \#MT10090CV) containing 10\% FBS, 1 mm sodium pyruvate (Thermo Fisher Scientific, catalog \#11360070), $1 \mathrm{~mm}$ geneticin (Thermo Fisher Scientific, catalog \#10131-035) and 1\% Anti-Anti. BHK cells (Baby Hamster Kidney Fibroblast) were a gift from Dr. Chongren Tang, HeLa cells were a gift from Dr. Alan Remaly, and C8 astrocyte cells were a gift from Dr. Jian Sima. BHK, HeLa and C8 cells were grown in DMEM containing 10\% FBS and 1\% Anti-Anti.

$q R T-P C R$. Immortalized and primary astrocytes expressing different ApoE isoforms were used to study ABCA1 expression at transcriptional level as described previously (Jiang et al., 2006). Cells were harvested and RNA was extracted using RNA extraction kit (Thermo Fisher Scientific, catalog \#12183018A). cDNA synthesis was done using High-Capacity cDNA Reverse Transcription Kit (Thermo Fisher Scientific, catalog \#4368814). ABCA1 expression was analyzed using primers of ABCA1 sense (5'-GCAAGGCTACCAATTACATTT G-3') and antisense (5' GGTCAGAAACATCACCTC CTG-3') as described previously (Jiang et al., 2006).

Cell surface protein preparation. To study cell surface proteins, biotinylation of cell surface proteins was performed as described earlier (Zhao et al., 2017). Briefly, cells were washed twice with cold PBS followed by incubation with $0.5 \mathrm{mg} / \mathrm{ml}$ sulfo-NHS-SS-biotin (Thermo Fisher Scientific, catalog \#PG82077) in PBS for 30 min at $4^{\circ} \mathrm{C}$ with shaking. Reaction was quenched by rinsing cells with $50 \mathrm{~mm}$ glycine in PBS. Then, cells were lysed with RIPA buffer (CST, catalog \#9806) containing protease inhibitor mixture, followed by centrifugation at $12,000 \mathrm{~g}$ for $10 \mathrm{~min}$. The supernatant was collected and protein concentrations were measured by BCA kit (Thermo Fisher Scientific, catalog \#23225). The RIPA fraction represents the total protein fraction. Then, $100 \mu \mathrm{g}$ of RIPA fraction from each sample was incubated with $100 \mu \mathrm{l}$ of Pierce NeutrAvidin agarose beads (Thermo Fisher Scientific, catalog \#29200) at $4^{\circ} \mathrm{C}$ for $2 \mathrm{~h}$. The beads were then washed 3 times with PBS containing protease inhibitor mixture followed by boiling samples with $2 \times$ SDS sample loading buffer. This fraction represents membrane protein. Analysis of membrane and total proteins were performed by Western blot.

$A B C A 1$ protein expression. Cell or tissue lysate were separated by $4-15 \%$ mini-precast protein gels (Bio-Rad, catalog \#4561086) under reducing conditions and then transferred onto nitrocellulose membranes (Bio-Rad, catalog \#1704270). After transfer, membrane was 
blocked with 5\% fat-free milk (Bio-Rad, catalog \#1706404) in TBST for $1 \mathrm{~h}$ at room temperature, followed by overnight incubation with primary antibody $(1: 1000)$ in $5 \% \mathrm{BSA}$ at $4^{\circ} \mathrm{C}$. Then, the membrane was incubated with HRP conjugated secondary antibody (1:2000) for $1 \mathrm{~h}$ at room temperature. Chemiluminescent HRP substrate (Millipore, catalog \#WBKLS0500) was used for detection. Fujifilm LAS-4000 Imager system was used to capture images and densitometric quantification was done using GelQuantNET software.

The following antibodies were used: anti-human ApoE antibody (Academy Bio-Medical, catalog \#A14 50A-G1b), anti-ABCA1 antibody (Abcam, catalog \#ab18180), anti- $\beta$-actin antibody (CST, catalog \#3700), anti-ARF6 antibody (CST, catalog \#5740), anti- $\beta$-Amyloid (6E10, BioLegend, catalog \#803001), HRP-linked anti-mouse IgG (CST, catalog \#7076), HRP-linked anti-rabbit IgG (CST, catalog \#7074), HRPlinked anti-goat IgG (Santa Cruz Biotechnology, catalog \#sc-2020).

Cholesterol efflux. ABCA1-mediated cholesterol efflux was measured using a previously published protocol (Yassine et al., 2016). Briefly, BHK cell lines transfected with a mifepristone switch to express ABCA1 were used. On day 1, cells were seeded at 5000 cells/well in 96-well plates. On day 2, cells were labeled with $1 \mu \mathrm{Ci} / \mathrm{ml}\left({ }^{3} \mathrm{H}\right)$ cholesterol (Moravek, catalog \#MT9112) using serum-free DMEM, $2 \mathrm{mg} / \mathrm{ml}$ fatty acid-free BSA (Sigma-Aldrich, catalog \#A9647), and $2 \mu \mathrm{g} / \mathrm{ml}$ acyl-coenzyme A: cholesterol acyltransferase inhibitor SANDOZ (Sigma-Aldrich, catalog \#S9318) for $24 \mathrm{~h}$. On day 3, ABCA1 was induced with $20 \mathrm{nmol} / \mathrm{L}$ mifepristone (Sigma-Aldrich, catalog \#M8046) for 18 h. On day 4, cells were treated with different reagents for $4 \mathrm{~h}$. After treatment, cell culture medium was collected and transferred to scintillation vials filled with $3 \mathrm{ml}$ of scintillation mixture. The cells were solubilized in $0.5 \mathrm{~N} \mathrm{NaOH}$ and neutralized with PBS, and then transferred to scintillation vials filled with $3 \mathrm{ml}$ of scintillation mixture. After rigorously mixed, the vials were counted in a Beckman LS6500 liquid scintillation counter (Beckman Coulter). The efflux of cholesterol was assessed by the ratio of cholesterol in the medium to total cholesterol (medium and cell lysate).

For studying cholesterol efflux in astrocytes, ApoE3 and ApoE4 primary astrocyte were plated and labeled with $\left({ }^{3} \mathrm{H}\right)$ cholesterol. Then, cells were treated with $2 \mu \mathrm{M}$ GW3965 (liver X receptor agonist) (SigmaAldrich, catalog \#G6295) for $24 \mathrm{~h}$. On the next day, cells were treated with media or CS-6253 peptide for $4 \mathrm{~h}$. Cholesterol efflux was measured as described above.

Transfections. Scrambled siRNA and ARF6 siRNA (CAAACGGGGUG GGGUAAUA) were obtained from Dharmacon. ApoE4 primary astrocytes were seeded in DMEM with $10 \%$ FBS. Transfections were performed $18 \mathrm{~h}$ later when cells were $70-80 \%$ confluent. Transfection of cells with scrambled and ARF6 siRNAs was done using jetPRIME reagent (Polyplus Transfection, catalog \#114). The final siRNA concentration was 200 nM. ARF6 protein expression was detected by Western blot $72 \mathrm{~h}$ after transfection. For cholesterol efflux experiments, primary ApoE4 astrocytes were plated at 6000 cells/well with DMEM in 96-well plates. On the following day, cells were transfected with scrambled or ARF6 siRNA and cholesterol efflux was performed as described above.

Immunofluorescence and colocalization. HeLa cells, stably transfected with ABCA1-GFP, were grown on poly-D-lysine-coated $12 \mathrm{~mm}$ glass coverslips in a 24 -well culture plate. After fixing with $4 \%$ paraformaldehyde, cells were permeabilized with $0.25 \%$ Triton X-100. Cells were then blocked with 5\% goat serum and incubated with Alexa-594 anti-human LAMP-2 antibody (BioLegend, catalog \#354309) or Rab11 polyclonal antibody (Thermo Fisher Scientific, catalog \#71-5300) overnight. On the day of imaging, cells were treated with $200 \mathrm{~nm}$ recombinant ApoE3 (rApoE3) or rApoE4 and/or $1 \mu \mathrm{M}$ CS-6253 peptide for $30 \mathrm{~min}$. Nuclei were stained with Hoechst 33258 blue (Thermo Fisher Scientific, catalog \#H3569). Images were taken using LSM 800 Zeiss and SP8 Leica confocal microscopes. Fluorescent image acquisition was done by a technical expert blinded to sample identities. Colocalization rate was quantified using Leica software application suite X (LAS-X). Difference between colocalization was calculated by subtracting the colocalization rate for different treatment conditions.

$A B C A 1$ and ApoE aggregation. To study aggregation of proteins, guanidine- $\mathrm{HCl}(\mathrm{GnHCl})$ soluble fractions were collected from rApoE isoforms, BHK cells, primary astrocytes, hippocampal homogenates or
CSF as described previously (Zhao et al., 2017). Briefly, $10 \mu \mathrm{g}$ of rApoE3 or rApoE4 were solubilized in $50 \mu \mathrm{l}$ of RIPA buffer containing protease inhibitor and incubated in a water bath at $37^{\circ} \mathrm{C}$ for $4 \mathrm{~h}$. The tubes were then centrifuged at $40,000 \mathrm{rpm}$ for $1 \mathrm{~h}$ at $4^{\circ} \mathrm{C}$. The supernatant collected represents the RIPA-soluble fraction. The pellets were then dissolved in $50 \mu \mathrm{l}$ of $5 \mathrm{M} \mathrm{GnHCl}$ and incubated for $4 \mathrm{~h}$. Then, samples were dialyzed overnight with PBS and concentrated down to $40 \mu$ l. This was designated as the $\mathrm{GnHCl}$-soluble fraction. For BHK cells and primary astrocytes, cells were lysed with RIPA after treatment. Then, $20 \mu \mathrm{l}$ of the RIPA fraction was centrifuged at $40,000 \mathrm{rpm}$ for $1 \mathrm{~h}$ at $4^{\circ} \mathrm{C}$. The supernatant was collected as the RIPA-soluble fraction. The pellets were then dissolved in $\mathrm{GnHCl}$, dialyzed and concentrated, and designated as the GnHCL-soluble fraction. For mouse hippocampus, $100 \mu \mathrm{g}$ of sample was used to collect RIPA and $\mathrm{GnHCl}$ fraction as described above. For human CSF, $200 \mu \mathrm{l}$ of CSF from 6 APOE $\varepsilon 3 / \varepsilon 3$ and 5 APOE $\varepsilon 4 / \varepsilon 4$ carriers was used for total protein extraction with $200 \mu$ lof RIPA and followed by $\mathrm{GnHCl}$ fraction extraction. ABCAl and ApoE in RIPA and $\mathrm{GnHCl}$ fractions were detected by Western blot.

Immunoprecipitation. BHK cells induced by mifepristone to express ABCA1 were incubated with $200 \mathrm{~nm}$ rApoE4 for $4 \mathrm{~h}$. Then, cells were lysed with RIPA and lysates were used for immunoprecipitation with an anti-human ApoE antibody. After elution, ApoE and ABCA1 were detected by Western blot.

Preparation of astrocyte conditioned medium (ACM). Immortalized ApoE3 or ApoE4 astrocytes were cultured. When cells were reached $80 \%$ confluency, the medium was removed, and cells were washed twice with PBS. New medium without FBS was added and cultured for $3 \mathrm{~d}$. Then, the medium was collected and centrifuged at $800 \mathrm{rpm}$ for $5 \mathrm{~min}$ to remove debris. The supernatant (ACM) was then concentrated 10 times using Protein Concentrator PES 10K MWCO (Thermo Fisher Scientific, catalog \#88527). Total protein concentration of ACM was measured by BCA kit. Then, equal amount of protein from ACM were loading into Native-PAGE and detected by anti-human ApoE antibody. The size of ApoE particles were measured using native gel standards (Thermo Fisher Scientific, catalog \#LC0725).

A 42 degradation assay. BHK cells were plated in 24-well plates at a density of $4 \times 10^{4} /$ well in DMEM containing $10 \%$ FBS. Cells were treated with or without mifepristone $(25 \mathrm{nM})$ for $12 \mathrm{~h}$ to induce ABCA1 expression. After washing once with PBS, A $\beta 42$ degradation was assessed after treating cells with soluble $\mathrm{A} \beta 42(2 \mu \mathrm{g} / \mathrm{ml})$ plus rApoE3 $(0.2 \mu \mathrm{M})$, rApoE4 $(0.2 \mu \mathrm{M})$ with or without CS-6253 peptide $(1 \mu \mathrm{M})$ for $24 \mathrm{~h}$ in DMEM containing $5 \mathrm{mg} / \mathrm{ml} \mathrm{BSA}$ as described previously (Jiang et al., 2008). On the following day, cells were washed extensively with PBS for 3 times and lysed in ice-cold RIPA buffer, then collected by centrifugation at $12000 \mathrm{rpm}$ at $4^{\circ} \mathrm{C}$ for $10 \mathrm{~min}$. Cell lysates were resolved in $4-15 \%$ Tris-glycine SDS-PAGE. A $\beta 42$ levels in the cell lysate were measured by Western blot using purified anti- $\beta$-Amyloid, $1-16$ antibody (BioLegend, 6E10).

C8 astrocyte cells were plated overnight in 24-well plates at a density of $6 \times 10^{4} /$ well in DMEM containing $10 \%$ FBS. Cells were then treated with rApoE3 $(0.2 \mu \mathrm{M})$, rApoE4 $(0.2 \mu \mathrm{M})$ with or without CS-6253 peptide $(1 \mu \mathrm{M})$ together with soluble A $\beta 42(2 \mu \mathrm{g} / \mathrm{ml})$ for $24 \mathrm{~h}$ in DMEM containing $5 \mathrm{mg} / \mathrm{ml} \mathrm{BSA}$. On the following day, cell lysates were collected and immunoblotted for A $\beta 42$ levels as described above.

Statistical analysis. Results are presented as the mean \pm SD. All data were analyzed using Student's $t$ test or ANOVA for group comparisons. Data from independent means were analyzed using unpaired $t$ tests or linear regression models. Nonparametric tests were used when the data were not normally distributed. We defined $p<0.05$ as statistically significant.

\section{Results}

ApoE4 associates with lower plasma membrane ABCA1 expression and recycling together with greater ARF6 protein expression

To investigate the effect of ApoE4 on ABCA1 expression, we first measured ABCA1 mRNA and protein levels in ApoE3 and ApoE4 immortalized astrocyte. The results showed ABCA1 mRNA and 
A

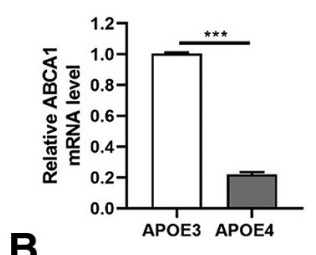

B

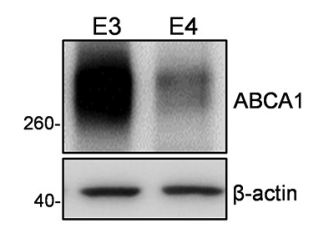

C
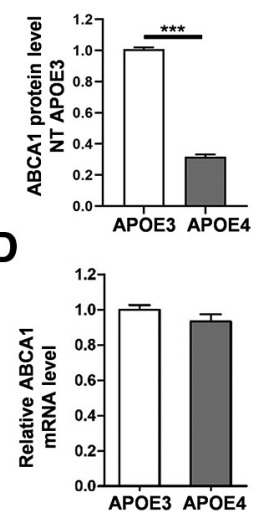

E

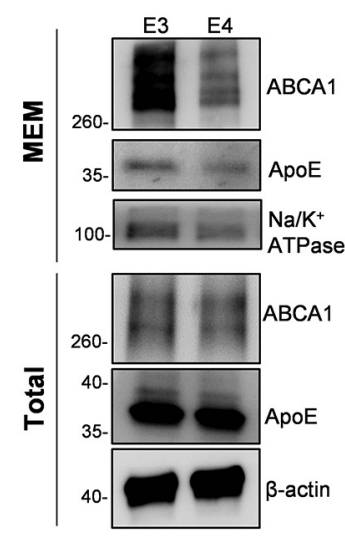

F

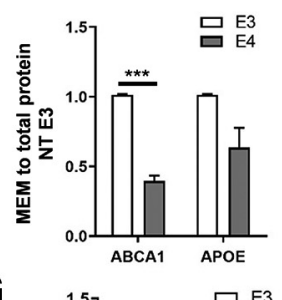

G

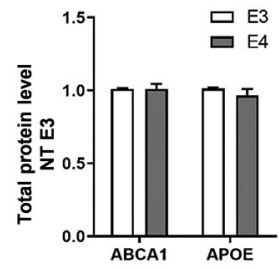

H
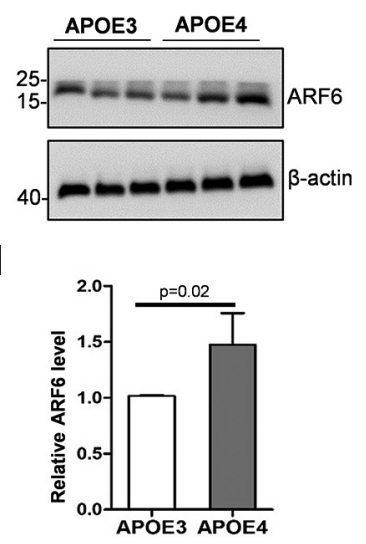

Figure 1. Membrane ABCA1 level decreased in ApoE4 primary astrocytes compared with ApoE3. A, ABCA1 mRNA level in ApoE3 and ApoE4 immortalized astrocytes was assessed by qRT-PCR. $\boldsymbol{B}$, Total ABCA1 protein in ApoE3 and ApoE4 immortalized astrocytes were detected by Western blot. $\boldsymbol{C}$, Densitometric quantification total ABCA1 protein of blotting shown in $\boldsymbol{B}$ from three independent experiments. D, ABCA1 mRNA level in ApoE3 and ApoE4 primary astrocytes was assessed by qRT-PCR. E, Membrane (MEM) and total ABCA1 and ApoE protein in ApoE3 and ApoE4 primary astrocytes were detected by Western blot. $\mathrm{Na} / \mathrm{K}^{+}$ATPase was used as the membrane protein loading control. In this immunoblot, the membrane fraction loaded was prepared from $3 / 8$ of total cell volume. The loaded total fraction was $1 / 10$ of total cell lysate volume. Actin was used as the total protein loading control. $\boldsymbol{F}, \boldsymbol{G}$, Densitometric quantification of membrane $(\boldsymbol{F})$ and total $(\boldsymbol{G})$ ABCA1 and ApoE protein of blotting shown in $(\boldsymbol{E})$ from three independent experiments. $\boldsymbol{H}$, ARF6 protein in ApoE3 and ApoE4 primary astrocytes was detected by Western blot. $\boldsymbol{I}$, Densitometric quantification of blotting shown in $(\boldsymbol{H})$ from three independent experiments. ${ }^{* * *} p<0.001$.

protein were significantly decreased in ApoE4 immortalized astrocytes compared with ApoE3 (Fig. 1A-C). We then cultured primary astrocytes from ApoE3 and ApoE4-TR mice and measured ABCA1 expression in these cells. ABCA1 mRNA and total protein levels did not differ between ApoE3 and ApoE4 primary astrocytes (Fig. $1 D$, bottom, and $G$ ). However, membrane ABCA1 levels were significantly lower in ApoE4 primary astrocytes compared with ApoE3 (Fig. $1 D$, top, and $F$ ). The observed difference in ABCA1 expression between primary and immortalized astrocytes could have resulted from the age of cells, as primary astrocytes are very young when cultured compared with the overall age of immortalized astrocytes.

To understand the lower membrane $\mathrm{ABCA} 1$ expression with ApoE4, we examined mechanisms of ABCA1 intracellular trafficking. Increased activation of the GTPase ARF6 has been implicated in diverting ABCA1 away from the plasma membrane and toward late endosomes (Mukhamedova et al., 2016). We found greater protein levels of ARF6 in ApoE4 primary astrocytes compared with ApoE3 primary astrocytes (Fig. $1 \mathrm{H}, \mathrm{I}$ ). To visualize the effect of ApoE isoforms on ABCA1 localization and recycling, HeLa cells transfected with GFP-tagged ABCA1 were treated with $0.2 \mu \mathrm{M}$ recombinant ApoE3 or ApoE4 for $30 \mathrm{~min}$. Greater colocalization of ABCA1 with the late endosome marker LAMP2 and lower colocalization with the recycling endosome marker Rab11 were observed in cells treated with rApoE4 compared with rApoE3 (Fig. 2). Together, these results indicated that ApoE4 induces greater ARF6 protein expression, a mechanism that favored trapping of ABCA1 in late-endosomes and decreased its recycling to the plasma membrane.

\section{ApoE4 associates with lower ABCA1-mediated cholesterol efflux and ApoE lipidation}

A primary function of ABCA1 is to transport cholesterol and phospholipids to apolipoprotein acceptor particles. We studied the effect of diminished ABCA1 membrane recycling on cholesterol efflux function. As expected, lower plasma membrane ABCA1 expression and recycling observed in ApoE4 primary astrocytes were associated with lower cholesterol efflux at $4 \mathrm{~h}$ (Fig.
$3 A$ ) and $24 \mathrm{~h}$ (Fig. 3B) compared with that of ApoE3. Knockdown of ARF6 by siRNA resulted in significant increase in cholesterol efflux in ApoE4 primary astrocytes after 4 and $24 \mathrm{~h}$ (Fig. 3C-E). To confirm the effect of ApoE4 on ABCA1-mediated cholesterol efflux, BHK cells induced by mifepristone to express ABCA1, were treated with $0.2 \mu \mathrm{M} \mathrm{rApoE} 4$ or rApoE3 for $4 \mathrm{~h}$. rApoE4treated cells exhibited significantly lower cholesterol efflux compared with cells treated with rApoE3 (Fig. $3 F$ ).

We previously identified that ABCA1-mediated cholesterol efflux capacity of CSF was lower in persons with AD compared with cognitively normal individuals (Yassine et al., 2016) but we did not examine the effect of APOE4 allele on cholesterol efflux in non-demented individuals. Here, we assessed whether CSF from non-demented APOE4 carriers was less efficient in inducing cholesterol efflux by ABCA1 than APOE4 noncarriers. Description of the participant characteristics is presented in Table 1. Mifepristone induced ABCA1 expressing BHK cells incubated with CSF from non-demented APOE $\varepsilon 4 / \varepsilon 4$ carriers $(n=3)$ showed significantly lower cholesterol efflux capacity compared with cells incubated with CSF from $\varepsilon 3 / \varepsilon 3$ carriers $(n=9)$ (Fig. $3 G)$. Notably a relatively large variability in cholesterol efflux capacity was observed from CSF of non-demented $\varepsilon 3 / \varepsilon 4$ carriers $(n=8)$.

To address whether lower ABCA1 activity had an effect on ApoE particle size, astrocyte conditioned media (ACM) from ApoE3 and ApoE4 immortalized astrocytes with equal amounts of ApoE were loaded onto Native PAGE to assess ApoE particle size. By native gel, ACM ApoE particles were separated into five distinct sizes: very large $\left(\alpha_{0}>1000 \mathrm{KDa}\right)$, large $\left(\alpha_{1} \sim 720 \mathrm{KDa}\right)$, medium $\left(\alpha_{2} \sim 480 \mathrm{KDa}\right)$, small $\left(\alpha_{3} \sim 242 \mathrm{KDa}\right)$ and very small $\left(\alpha_{4} \sim 35 \mathrm{KDa}\right)$ (Fig. $\left.3 H\right)$. Between ACM from ApoE3 and ApoE4 astrocytes, there was no significant differences in percentage of total ApoE present as $\alpha_{0}$ and $\alpha_{1}$ (Fig. $3 I, J$ ). However, ACM from ApoE4 astrocytes had significantly lower percentage of ApoE as $\alpha_{2}$ (Fig. $3 \mathrm{~K}$ ) and $\alpha_{3}$ (Fig. $3 \mathrm{~L}$ ) and a greater percentage as $\alpha_{4}$ (Fig. $3 M$ ) compared with ApoE3 astrocytes. Together, these findings indicated that ApoE4 astrocytes had lower ABCA1 cholesterol efflux capacity and a greater percentage of lipid-poor ApoE. 
A

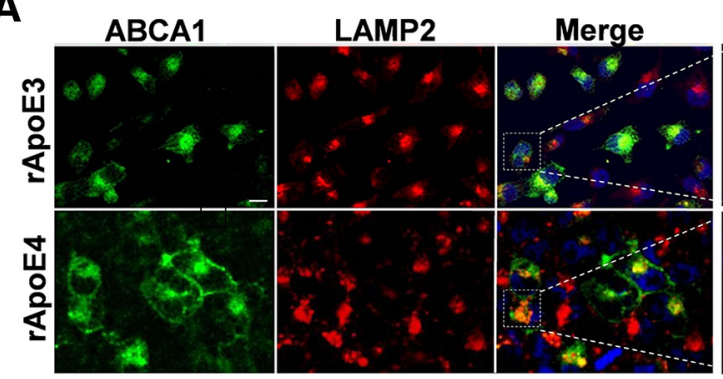

C

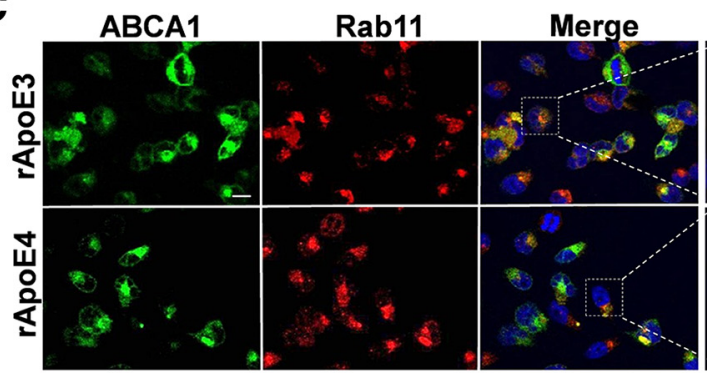

B
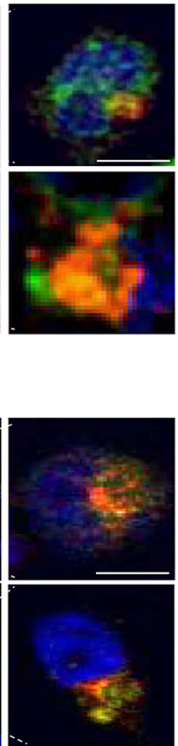

D
ABCA1 with LAMP2
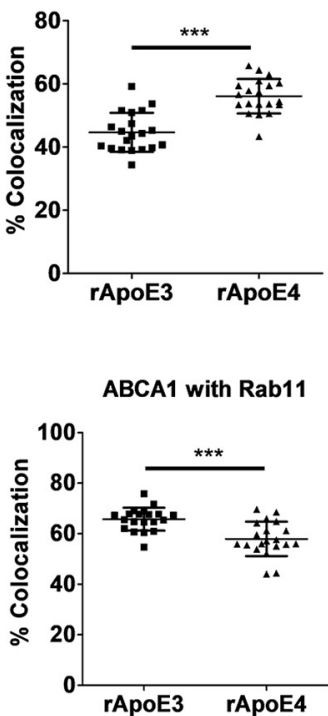

Figure 2. Recombinant ApoE4 trapped more ABCA1 in lysosome than ApoE3. HeLa cells expressing GFP-tagged ABCA1 were treated with $0.2 \mu \mathrm{m}$ rApoE3 or rApoE4 for 30 min. The colocalization of ABCA1 with LAMP2 (lysosomal marker) $(\boldsymbol{A}, \boldsymbol{B})$ or Rab11 (recycling vesicle marker) $(C, D)$ was calculated using confocal microscopy. ${ }^{* * *} p<0.001$.

A

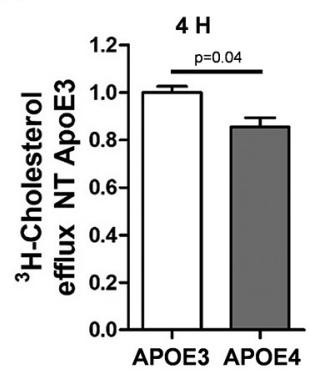

$\mathbf{F}$

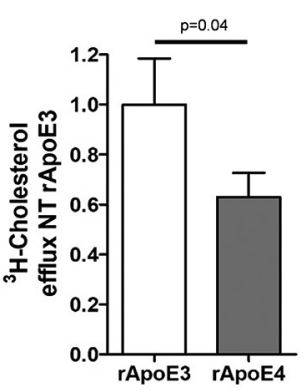

B

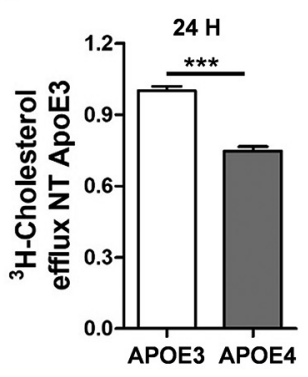

G

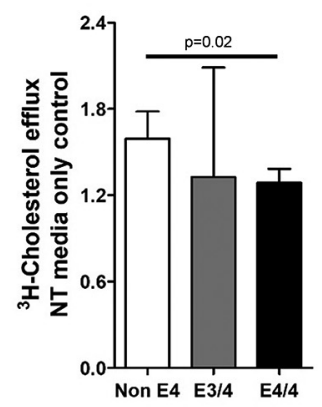

C

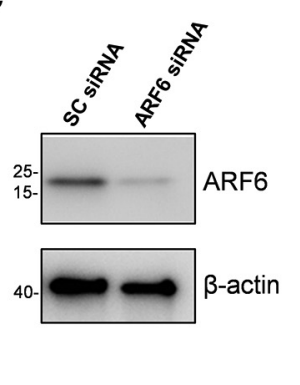

H

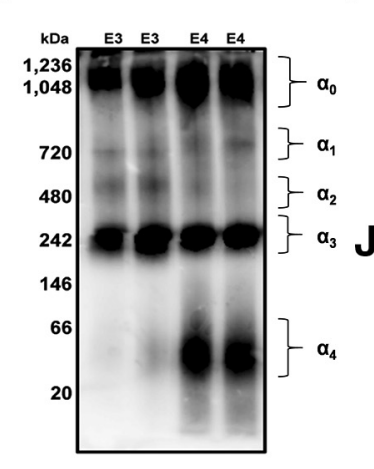

D

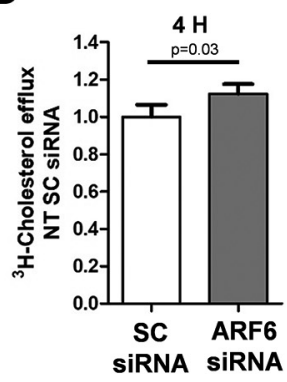

K

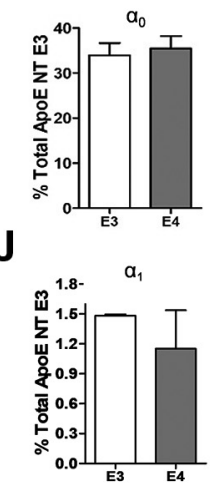

E
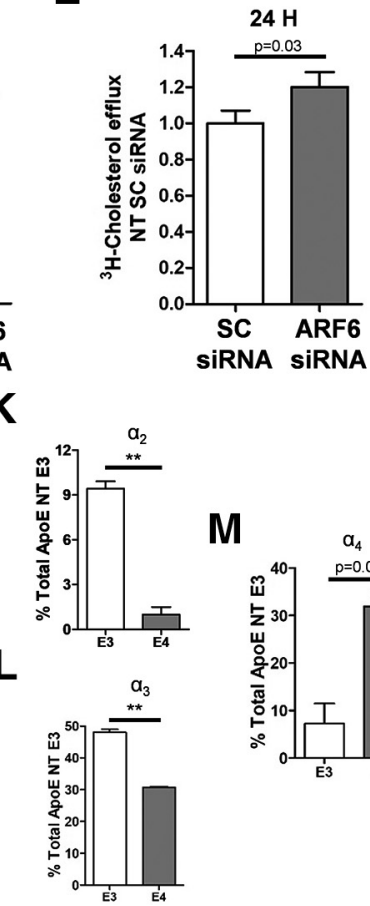

M

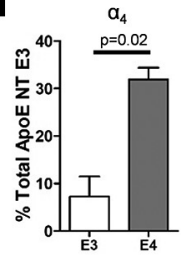

Figure 3. Effect of ApoE isoforms on ABCA1-mediated cholesterol efflux and ApoE lipidation. $A, B, A p o E 3$ or ApoE4 primary astrocyte were seeded overnight in 96-well plates and then incubated with $3 \mathrm{H}$-labeled cholesterol for $24 \mathrm{~h}$. After washing with PBS, DMEM containing $2 \mathrm{mg} / \mathrm{ml} \mathrm{BSA}$ were added to the wells and cholesterol efflux was measured at $4 \mathrm{~h}(\boldsymbol{A})$ and $24 \mathrm{~h}(\boldsymbol{B})$. Values showed are normalized to the ApoE3 group. C, ApoE4 mouse primary astrocytes were treated with ARF6 siRNA for 48 h and ARF6 expression was measured by Western blot. $\boldsymbol{D}$, $\boldsymbol{E}$, ApoE4 primary astrocyte were treated with ARF6 siRNA followed by cholesterol efflux measurement at $4 \mathrm{~h}(\boldsymbol{D})$ and $24 \mathrm{~h}(\boldsymbol{E})$. $(\boldsymbol{F}, \boldsymbol{G})$ BHK cells were labeled with ${ }^{3} \mathrm{H}$-cholesterol followed by induction of $\mathrm{ABCA} 1$ expression, and then cholesterol efflux was determined after treatment with $0.2 \mu \mathrm{m}$ recombinant ApoE3 or ApoE4 (F) or with $15 \mu$ l of CSF from non- $\varepsilon 4(n=9)$, $\varepsilon 3 / \varepsilon 4(n=8)$, and $\varepsilon 4 / \varepsilon 4$ carriers $(n=3)(\boldsymbol{G})$ for $4 \mathrm{~h}$. $\boldsymbol{H}$, ApoE HDL particles in astrocyte conditioned medium (ACM) from ApoE3 or ApoE4 immortalized astrocytes were analyzed by native-PAGE followed by anti ApoE Western blot. ApoE particles were separated into five distinct sizes, very large ( $\left.\alpha_{0}>1000 \mathrm{KDa}\right)$, large $\left(\alpha_{1} \sim 720 \mathrm{KDa}\right)$, medium $\left(\alpha_{2} \sim 480 \mathrm{KDa}\right)$, small $\left(\alpha_{3} \sim 242 \mathrm{KDa}\right)$ and very small $\left(\alpha_{4} \sim 35 \mathrm{KDa}\right)$. I-M, Densitometric quantification of different size of ApoE particles of blotting shown in $\boldsymbol{H}$ from three independent experiments. ${ }^{* *} p<0.01$; ${ }^{* *} p<0.001$.

ApoE4 associates with increased aggregation of ApoE and $A B C A 1$

To test whether ApoE directly interacted with ABCA1 to promote its aggregation, immunoprecipitation of ApoE and ABCA1 was performed. ABCA1 expressing BHK cells were treated with 0.2 $\mu \mathrm{M}$ recombinant human ApoE4 for $4 \mathrm{~h}$, and ApoE4 protein from cell lysates were pulled down using an anti-human ApoE antibody. ApoE and ABCA1 were detected in the elute complex. The 


Table 1. Characteristics of participants in the ABCA1 mediated cholesterol efflux
study
\begin{tabular}{lllll}
\hline Genotype & Non-E4 & $\mathrm{E} 3 / 4$ & $\mathrm{E} 4 / 4$ & $p$-value \\
\hline Sample size & 9 & 8 & 3 & \\
Age (y) & $72 \pm 9$ & $77 . \pm 7$ & $64 \pm 6$ & 0.08 \\
Education (y) & $18 \pm 3$ & $15 \pm 2$ & $16 \pm 2$ & 0.143 \\
Gender (female/male) & $4 / 6$ & $8 / 1$ & $3 / 0$ & 0.08 \\
Race & & & & \\
$\quad$ Caucasian & 10 & 7 & 1 & \\
$\quad$ African American & 0 & 0 & 1 & \\
$\quad$ Asian & 0 & 1 & 0 & \\
$\quad$ Other & 0 & 1 & 1 & \\
\hline
\end{tabular}

All participants were nondemented with a clinical dementia rating score of 0 .

Data are presented as means $\pm S D$.

results revealed ApoE binding to ABCA1 (Fig. 4A). We then treated ABCA1 expressing BHK cells with rApoE3 or rApoE4 for $4 \mathrm{~h}$, and the RIPA and $\mathrm{GnHCl}$ fraction of the cell lysates were collected. ABCA1 level in RIPA fraction did not differ between rApoE3 and rApoE4 treatment. The ratio of ABCA1 in the Gn$\mathrm{HCl}$ to RIPA fractions was greater in cells treated with rApoE4 compared with rApoE3 (Fig. $4 B, C$ ). We then examined whether these observations are present in primary astrocytes and mouse brain homogenates. The relative amount of aggregated ABCA1 and ApoE were significantly increased in ApoE4 primary astrocytes compared with ApoE3 primary astrocytes (Fig. $4 D, E$ ). In agreement, the relative amounts of aggregated ABCA1 and ApoE were greater in hippocampal homogenates of male ApoE4-TR mice $(n=8)$ compared with ApoE3-TR mice $(n=6)$ (Fig. $4 F, G)$.

ApoE4 has an unstable hydrophobic core segment at the $\mathrm{N}$ terminus that is more prone to forming protein aggregates than ApoE3 (Hatters et al., 2006). This propensity of apoE4 to aggregate is amplified in the acidic compartment of endosomes (Morrow et al., 2002). rApoE4 protein formed more aggregates than rApoE3 protein when incubated ex vivo for $4 \mathrm{~h}$ at $37^{\circ} \mathrm{C}$, although the observed increase in ApoE4 aggregation were not statistically significant ( $p=0.2$; Fig. $4 H, I)$. We then examined ApoE protein aggregation in human CSF from age and sex matched $A P O E$ $\varepsilon 3 / \varepsilon 3(n=6)$ and $\varepsilon 4 / \varepsilon 4(n=5)$ carriers. The results revealed greater percentage of aggregated ApoE protein in CSF of $\varepsilon 4 / \varepsilon 4$ carriers (2.5-fold increased) compared with $\varepsilon 3 / \varepsilon 3$ carriers (Fig. $4 J, K)$. In summary, ApoE4 was present in more aggregated form than ApoE3 in primary astrocytes, mouse brain homogenates and in human CSF. ApoE4 aggregates complexed with ABCA1, providing a potential mechanism by which ApoE4 trapped ABCA1 intracellularly and decreased its ability to recycle to the plasma membrane and efflux cholesterol.

Treatment of ApoE4 cells with CS-6253 preserves membrane ABCA1 expression and enhances ABCA1 recycling

We previously identified that treatment of ApoE4-TR mice with the ABCA1 agonist CS-6253 had neuroprotective effects without affecting total ApoE or ABCA1 expression (Boehm-Cagan et al., 2016). Here, we examined the effect of the ABCA1 agonist CS6253 on ABCA1 membrane expression, recycling and cholesterol efflux function in ApoE4 cells. ApoE4 primary astrocytes were treated with CS-6253 for $4 \mathrm{~h}$ followed by labeling with biotin and incubating with NeutrAvidin agarose beads. The cell membrane protein was collected and detected with anti-ApoE and ABCA1 antibodies. CS-6253 increased the relative amount of ABCA1 on plasma membrane and significantly decreased total ARF6 protein expression in ApoE4-treated cells (Fig. 5A-C). CS-6253 had no effect on total ABCA1 protein levels (Fig. $5 A, C$ ). In ApoE4 im- mortalized astrocytes, treatment with $1 \mu \mathrm{M}$ CS-6253 increased ABCA1 stability. After 2 or 4 h of treatment with cycloheximide $(\mathrm{CHX})$ to inhibit new protein synthesis, ABCA1 levels were at $43 \%$ and $35 \%$ of baseline levels. Co-treatment with CS- 6253 for 2 or $4 \mathrm{~h}$ increased ABCA1 level to $80 \%$ and $79 \%$ of the baseline level (Fig. 5D,E).

To understand the effect of CS-6253 on ABCA1 endosomal recycling, HeLa cells transfected with GFP-tagged ABCA1 were treated with rApoE4 $(0.2 \mu \mathrm{M})$ with or without CS-6253 peptide ( 1 $\mu \mathrm{M})$ for $30 \mathrm{~min}$. ABCA1 and Rab11 were detected by confocal microscopy. Compared with cells treated with rApoE4 only, ABCA1 colocalization with Rab11 significantly increased by $11 \%$ upon cotreating cells with rApoE4 plus CS-6253 and by $12 \%$ with CS-6253 alone (Fig. 6A,B).

\section{Treatment of ApoE4 cells with CS-6253 enhances ABCA1- mediated cholesterol efflux}

Our results in HeLa cells indicated that CS-6253 stabilizes plasma membrane ABCA1 by promoting its recycling to the plasma membrane. We examined whether treatment with CS-6253 enhanced ABCA1-mediated cholesterol efflux in ApoE4 astrocytes. We first induced ABCA1 expression by treatment with the LXR agonist GW3965 and found no change in cholesterol efflux ability compared with media treatment. In contrast, treatment with 1 $\mu \mathrm{M}$ CS-6253 alone or cotreatment with GW3965 and CS-6253 together significantly increased cholesterol efflux compared with medium only (Fig. 7A). These results suggest that enhancing the LXR/RXR system by GW3965 to increase ABCA1 expression may not be sufficient to counteract the reduced capacity of ApoE4 to facilitate ABCA1-mediated cholesterol efflux, knowing that enhancing the LXR/RXR pathway increases both ABCA1 and ApoE protein expression (Mandrekar-Colucci and Landreth, 2011). In contrast, treatment with the ABCA1 agonist CS-6253 significantly enhanced cholesterol efflux in ApoE4 cells.

We then tested whether cholesterol efflux in ApoE4 astrocytes can be increased after both the inhibition of ARF6 and the addition of CS-6253. ApoE4 primary astrocytes had a small but significant increase in cholesterol efflux after reducing ARF6 protein and the addition of CS-6253 (Fig. 7B). The effects of CS-6253 on ABCA1 recycling were therefore not completely dependent on lowering of ARF6. Cholesterol efflux was then assessed in ABCA1 expressing BHK cells after treatment with $0.2 \mu \mathrm{M}$ rApoE4 with and without CS-6253 treatment. The cholesterol efflux capacity was significantly increased by co-treatment with $1 \mu \mathrm{M}$ CS-6253 (Fig. 7C).

These findings were then corroborated using human CSF from cognitively normal human participants carrying $\varepsilon 4 / \varepsilon 4$ (sample set description is listed in Table 1). Upon addition of CS-6253 peptide ex vivo, BHK cells incubated with CSF from non- $\varepsilon 4$ carriers showed an increase of $69 \%(n=7)$ compared with no peptide treatment, which was significantly greater than an increase of $32 \%(n=3)$ observed in CSF from $\varepsilon 4 / \varepsilon 4$ carriers treated with CS-6253. CS-6253 had the largest effect on ABCA1 cholesterol efflux when incubated with CSF from $\varepsilon 3 / \varepsilon 4$ carriers (Fig. 7D). In summary, the ABCA1 agonist CS-6253 enhanced ABCA1 cholesterol efflux in both ApoE3 and ApoE4. The addition of CS-6253 ex vivo to augment ABCA1-mediated cholesterol efflux by human CSF was least pronounced in $\varepsilon 4 / \varepsilon 4$ carriers.

\section{Treatment with CS-6253 decreases the aggregation of ApoE4 and $\mathrm{ABCA} 1$ in vivo}

Cotreatment of ABCA1 expressing BHK cells with rApoE4 and CS-6253 peptide for $4 \mathrm{~h}$ reduced the amount of ABCA1 pres- 
A

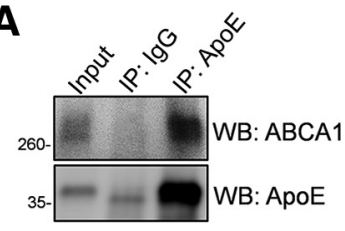

B

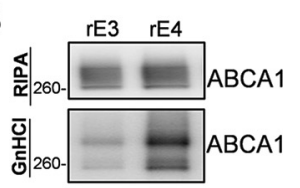

C

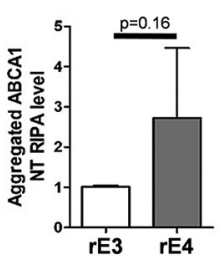

D
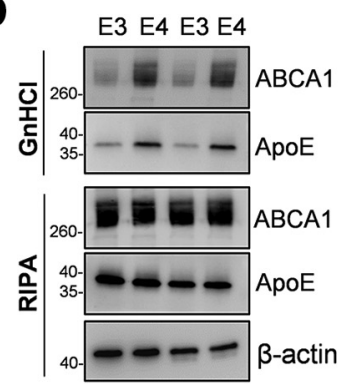

E

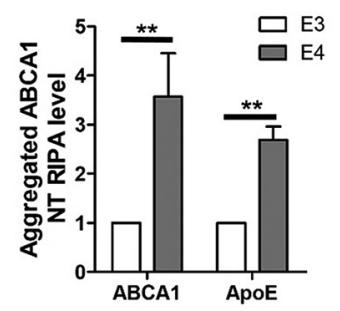

F
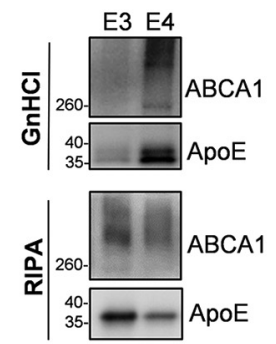

G

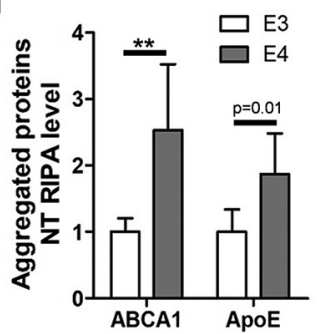

H

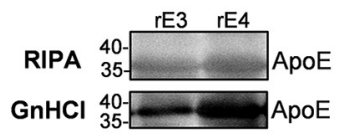

I
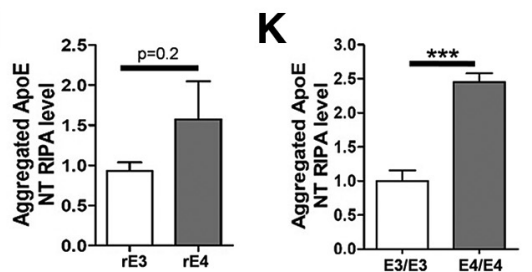

J

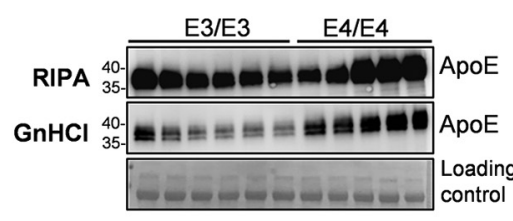

Figure 4. ApoE4 binds with ABCA1 and causes ABCA1 aggregation. A, ABCA1-expressing BHK cells were incubated with $\mathrm{rApoE} 4(0.2 \mu \mathrm{M})$ for $4 \mathrm{~h}$. Cells were collected and lysed with RIPA buffer. Immunoprecipitation was performed in the cell lysate using anti-human ApoE antibody or species-matched IgG. ABCA1 and ApoE were codetected after immunoprecipitation by Western blot. $B, A B C A 1-e x p r e s s i n g ~ B H K$ cells were treated with rApoE3 or rApoE4 for $4 \mathrm{~h}$. RIPA and GnHCl-soluble cell lysate were collected and ABCA1 in each fraction was detected by Western blot. C, Densitometric quantification of Western blot shown in $\boldsymbol{B}$ from three independent experiments. D, RIPA and GnHCl fraction from ApoE3 and ApoE4 primary astrocytes were collected and ABCA1 and ApoE proteins were detected by Western blot. $\boldsymbol{E}$, Densitometric quantification of Western blot shown in $\boldsymbol{D}$ from three independent experiments. $\boldsymbol{F}$, RIPA and GnHCl fraction from the hippocampus of ApoE3-TR $(n=6)$ and ApoE4-TR $(n=8)$ mice were collected and ABCA1 and ApoE proteins were detected by Western blot. $\boldsymbol{G}$, Densitometric quantification of Western blot shown in $\boldsymbol{F}$ from three independent experiments. $\mathrm{H}$, rApoE3 and rApoE4 $(10 \mu \mathrm{g})$ were solubilized in RIPA buffer and incubated at $37^{\circ} \mathrm{C}$ for $4 \mathrm{~h}$. RIPA and $\mathrm{GnHCl}$ fractions were subsequently collected and followed by ApoE detection by Western blot. $\boldsymbol{I}$, Densitometric quantification of Western blot shown in $\boldsymbol{H}$ from three independent experiments. $\boldsymbol{J}$, ApoE protein levels in RIPA and GnHCl fraction from the CSF of individuals carrying APOE $\varepsilon 3 / \varepsilon 3$ carrier $(n=6)$ and $A P O E \varepsilon 4 / \varepsilon 4(n=5)$ were detected by Western blot. $\boldsymbol{K}$, Densitometric quantification of Western blot shown in $\boldsymbol{J}$ from two independent experiments. Ponceau staining was used as the loading control. ${ }^{* *} p<0.01 ;{ }^{* * *} p<0.001$.

A

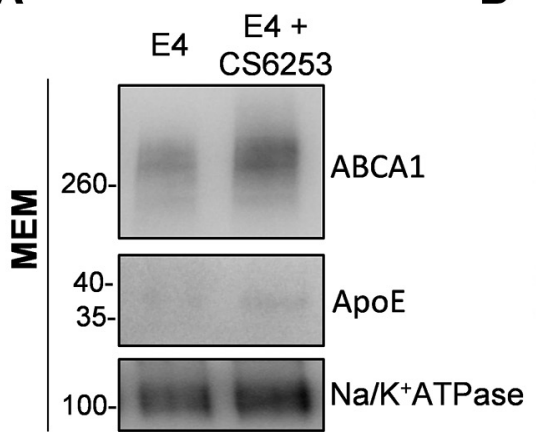

C

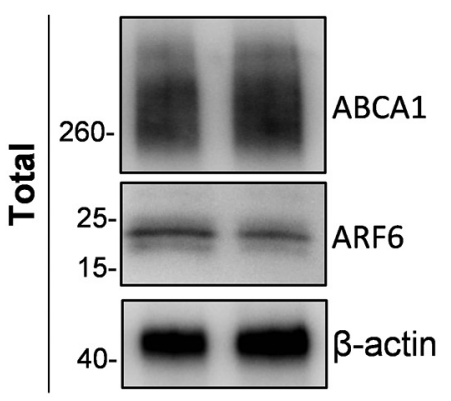

B
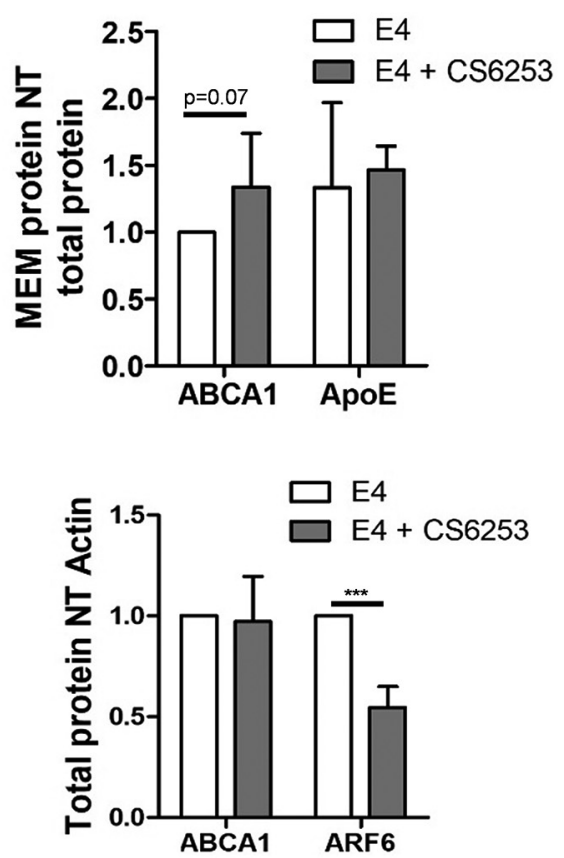

D

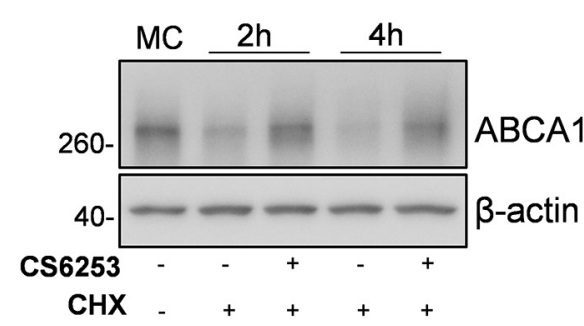

E

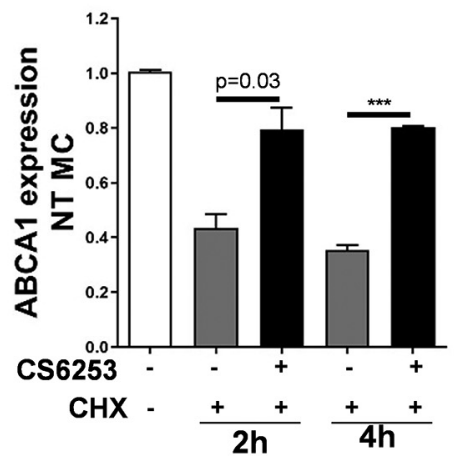

Figure 5. Effect of CS-6253 on ABCA1 expression and trafficking. A, ApoE4 primary astrocytes were treated with CS-6253 peptide ( $1 \mu \mathrm{M})$ for $4 \mathrm{~h}$ and then the membrane and total cellular protein were collected. ABCA1, ApoE, and ARF6 were detected by Western blot. B, C, Quantification of membrane ABCA1 and ApoE (B) and total ABCA1 and ARF6 (C) by Western blot shown in $A$ from three independent experiments. D, ApoE4 immortalized astrocytes were treated with CHX with and without CS-6253 for 2 and $4 \mathrm{~h}$. ABCA1 protein expression in cell lysates was detected by Western blot. $\boldsymbol{E}$, Quantification of Western blot shown in $\boldsymbol{D}$ from three independent experiments. ${ }^{* *} p<0.001$. 
A

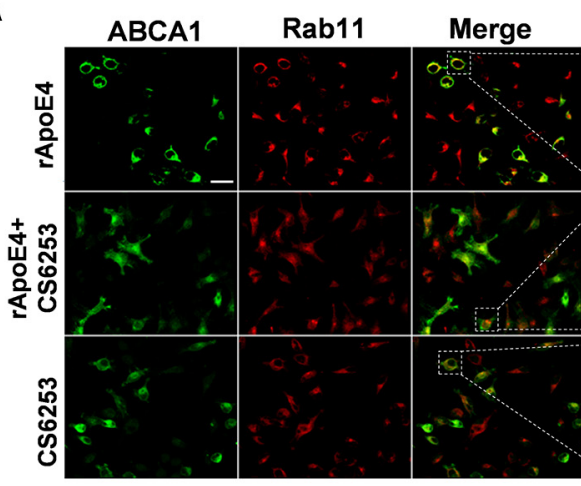

B

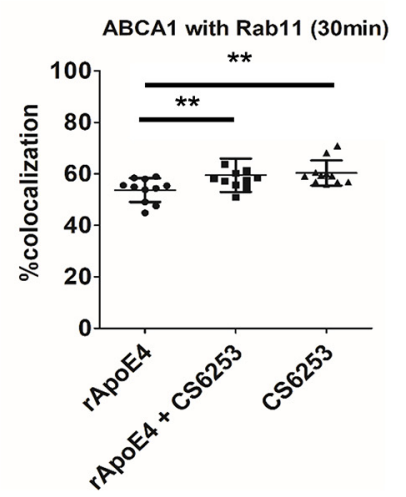

Figure 6. Effect of CS-6253 on ABCA1 trafficking. A, HeLa cells expressing GFP-tagged ABCA1 were treated with $0.2 \mu \mathrm{m}$ recombinant ApoE4 and/or $1 \mu \mathrm{M}$ CS-6253 peptide for 30 min. The colocalization of ABCA1 with Rab11 was calculated using confocal microscopy. B, Quantification of colocalization of ABCA1 with Rab11 from confocal experiments. ${ }^{* *} p<0.01$.

A

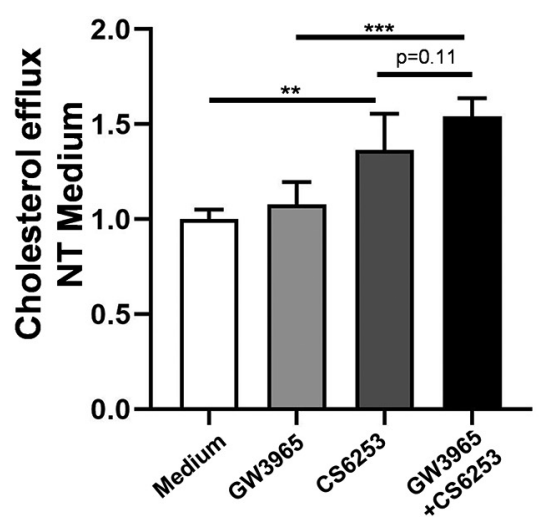

C

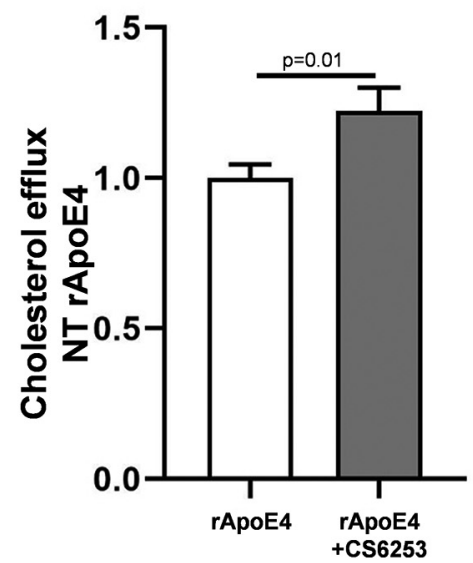

B
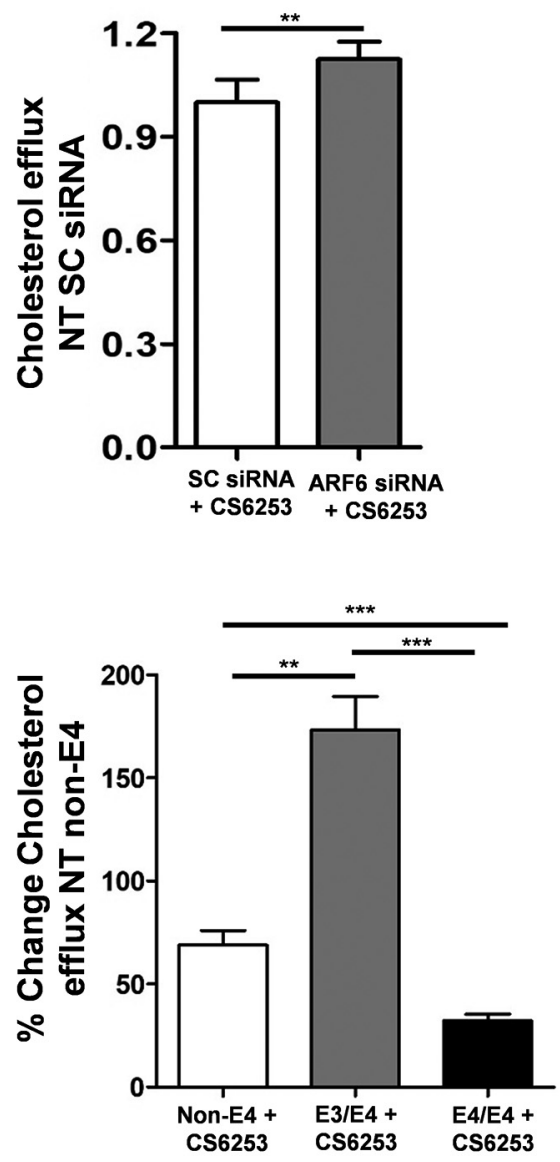

Figure 7. Effect of CS-6253 on cholesterol efflux function. A, ApoE4 primary astrocytes were incubated with ${ }^{3} \mathrm{H}$-labeled cholesterol for $24 \mathrm{~h}$. The cells were induced to express $\mathrm{ABCA} 1$ by GW3965 compound for $18 \mathrm{~h}$. After washing with PBS, cholesterol efflux were determined after treatment with or without CS-6253 (1 $\mu \mathrm{M})$ for $4 \mathrm{~h} . \boldsymbol{B}$, ApoE4 mouse primary astrocytes were treated with ARF6 siRNA or scramble siRNA followed by labeling with ${ }^{3} \mathrm{H}$-cholesterol for $24 \mathrm{~h}$. After washing with PBS, cholesterol efflux was measured after the addition of CS-6253 for $4 \mathrm{~h}$. C, D, BHK cells were labeled with ${ }^{3} \mathrm{H}$-cholesterol and $\mathrm{ABCA} 1$ expression was induced by mifepristone for $18 \mathrm{~h}$. Cholesterol efflux was measured after treatment with $0.2 \mu \mathrm{m}$ rApoE4 with or without $1 \mu \mathrm{M} \mathrm{CS}-6253$ (C) or after treatment with $1 \mu \mathrm{M}$ CS-6253 plus CSF from $\varepsilon 3 / \varepsilon 3(n=7), \varepsilon 3 / \varepsilon 4(n=8)$, or $\varepsilon 4 / \varepsilon 4(n=3)$ carriers $(\boldsymbol{D})$ for $4 \mathrm{~h} .{ }^{* *} p<0.01$; ${ }^{* * *} p<0.001$.

ent in aggregates by $30 \%$ compared with cells treated with rApoE4 only (Fig. $8 A, B$ ). Similarly, hippocampal homogenates from 4 months old male ApoE4-TR mice treated with CS-6253 had lower relative amounts of ABCA1 and ApoE in aggregates (47\% lower ABCA1, and 53\% less ApoE) than ApoE4-TR mice control (Fig. $8 C-E$ ). There was no significant difference in the levels of ABCA1 or ApoE in the RIPA soluble fraction adjusted to total protein (Fig. $8 F, G$ ). The percentage of ABCA1 and ApoE in aggregates was positively correlated $\left(r^{2}=0.44\right)$ (Fig. $8 H$ ). A representative blot of soluble and aggregated ApoE and ABCA1 with total proteins is presented in Fig. 8-1, available at https://doi.org/10.1523/JNEUROSCI.1400-19.2019.f8-1. 

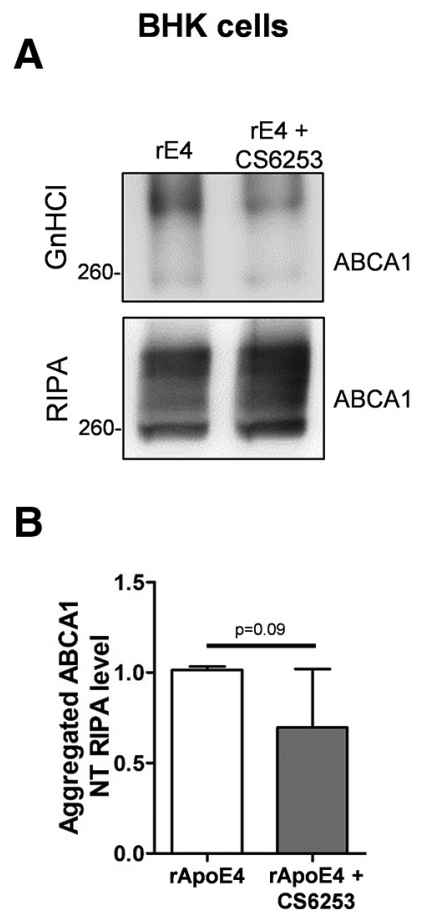
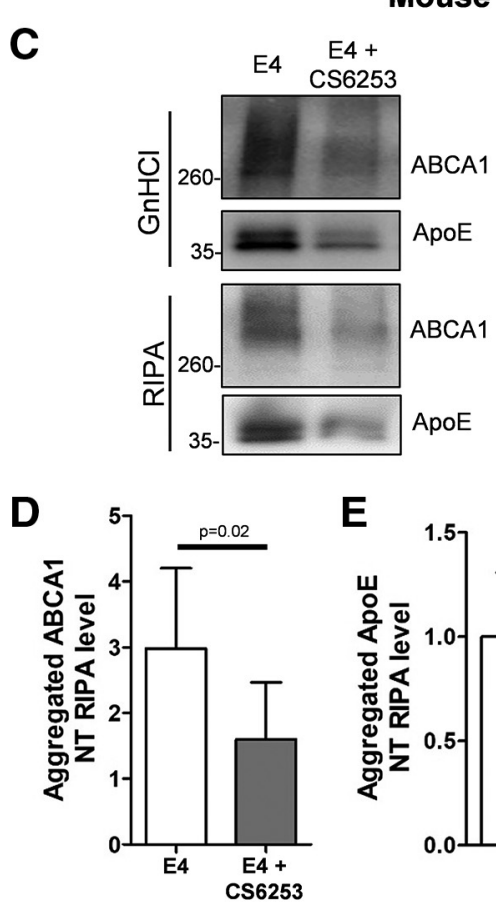
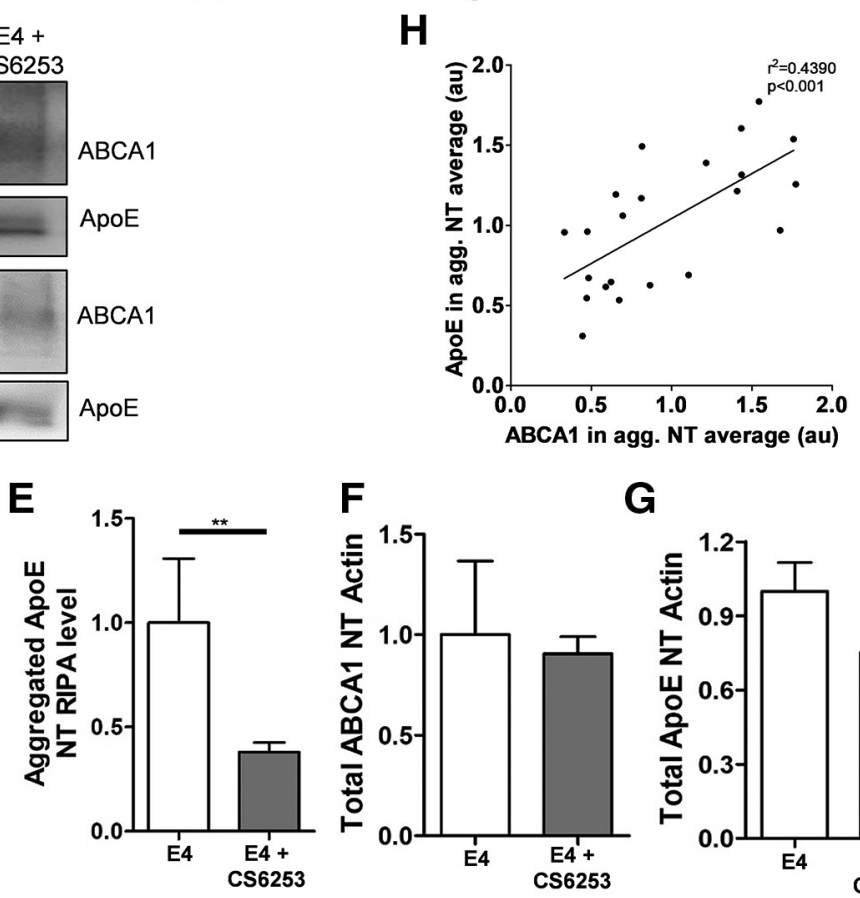

Figure 8. Effect of CS-6253 on ABCA1 aggregation. $A, A B C A 1$-expressing BHK cells were treated with $0.2 \mu \mathrm{m}$ rApoE4 with or without $1 \mu \mathrm{m}$ CS-6253 for $4 \mathrm{~h}$. RIPA and GnHCl fractions of the cell lysates were collected and $A B C A 1$ was detected by Western blot. $\boldsymbol{B}$, Densitometric quantification by Western blot is shown in $\boldsymbol{A}$ from three independent experiments. $\boldsymbol{C}$, ApoE4-TR mice were treated with vehicle $(n=8)$ or CS-6253 $(n=6)(20 \mathrm{mg} / \mathrm{kg} / 48 \mathrm{~h})$ for 6 weeks. Mouse hippocampus homogenates were separated into RIPA and GnHCl fractions. ABCA1 and ApoE in each fraction were detected by Western blotting. D-G, Densitometric quantification of Western blot shown in $\mathbf{C}$. $\boldsymbol{H}$, Correlation of ABCA1 and ApoE in aggregates. ${ }^{* *} p<0.01$. Figure 8-1 (available at https://doi.org/ 10.1523/JNEUROSCI.1400-19.2019.f8-1) in the extended data shows a representative immunoblot for ABCA1 and ApoE proteins in soluble and aggregated fractions from mouse hippocampal homogenates of ApoE-TR mice.

\section{Treatment with CS-6253 rescues impaired A $\beta 42$ degradation in ApoE4-treated cells}

The ability to efflux cholesterol by ABCA1 is associated with the capacity to degrade A $\beta 42$ (Lee et al., 2012). ApoE4 cells are less efficient in promoting intracellular $\mathrm{A} \beta 42$ degradation compared with ApoE3 cells (Jiang et al., 2008). We sought to determine whether the lower ABCA1 activity in ApoE4 compared with ApoE3 resulted in lower $A \beta 42$ degradation capacity and whether enhancing ABCA1 activity in ApoE4 can rescue this degradation impairment. First, we tested the effect of ABCA1 expression on the ability of ApoE3 or ApoE4 to facilitate intracellular $A \beta 42$ degradation. BHK cells were seeded in 24-well plates and treated with or without mifepristone to induce ABCA1 expression. Cells were then treated with $\mathrm{A} \beta 42$ and either control media, $0.2 \mu \mathrm{M}$ rApoE3, rApoE4 or rApoE4 and $1 \mu \mathrm{M} \mathrm{CS}-6253$ for $24 \mathrm{~h}$. Without ABCA1 expression, intracellular $A \beta$ levels significantly decreased after treatment with different apolipoproteins or CS-6253, but no difference was observed between rApoE3 or rApoE4-treated cells. However, after inducing ABCA1 expression by mifepristone, rApoE3 treatment showed significantly lower intracellular A $\beta 42$ levels compared with vehicle or rApoE4 treatment conditions (Fig. 9A,B). CS-6253 cotreatment with rApoE4 significantly lowered intracellular $A \beta 42$ levels compared with $\mathrm{rApoE} 4$ treatment alone (Fig. 9A, $B$ ).

Then, we confirmed these observations in $\mathrm{C} 8$ immortalized astrocytes. First, we verified that C8 astrocytes expressed ABCA1 (Fig. 9C). Subsequently, C8 astrocytes were treated with either control media, $0.2 \mu \mathrm{M}$ rApoE3, rApoE4 or rApoE4 and $1 \mu \mathrm{M}$ CS-6253 for $24 \mathrm{~h}$ as described above and cell lysates were collected and immunoblotted for $\mathrm{A} \beta 42$ levels. Compared with vehicle, $\mathrm{rApoE} 3$ treatment resulted in less intracellular $A \beta 42$ levels, whereas
rApoE4 treatment resulted in greater intracellular $A \beta 42$ levels. The data indicated that ApoE4 impeded $A \beta 42$ degradation (Fig. $9 D, E)$. Co-treatment of rApoE4 with CS-6253 significantly decreased A $\beta 42$ levels comparable to rApoE3 and lower than treatment with media only (Fig. $9 D, E$ ). In summary, these findings indicated that the differences between ApoE3 and ApoE4 in A $\beta 42$ degradation are dependent on ABCA1 expression and that enhancing ABCA1 activity by CS-6253 can rescue A $\beta 42$ degradation impairment in ApoE4.

\section{Discussion}

Lipid-poor ApoE4 is more prone to forming aggregates than ApoE3 (Morrow et al., 2002; Hatters et al., 2006; Hubin et al., 2019; Raulin et al., 2019) predisposing ApoE4 to develop AD pathology, but the mechanisms that regulate ApoE lipidation and aggregation in vivo are not well understood. In this work, we identified that ApoE4 associates with lower cell membrane ABCA1 expression secondary to an increase in an ARF6-mediated trafficking of ABCA1 to late endosomes as opposed to recycling endosomes. This was associated with lower ABCA1-mediated cholesterol efflux function, greater formation of hypolipidated ApoE particles, greater ApoE and ABCA1 protein coaggregation and reduced intracellular $A \beta 42$ degradation. Treatment with the ABCA1 agonist CS-6253 rescued ABCA1 from ApoE4 aggregation by decreasing ARF6 expression and promoting ABCA1 recycling to the plasma membrane to enhance its ability to efflux cholesterol (as illustrated in Fig. 10). This was accompanied by an enhanced ability to degrade $A \beta 42$. Importantly, restoring ABCA1 recycling was associated with a reduction in both ApoE and ABCA1 aggregation in ApoE4-TR mouse brain. These findings reveal novel insights into how ApoE4 alters ABCA1 function pro- 
A

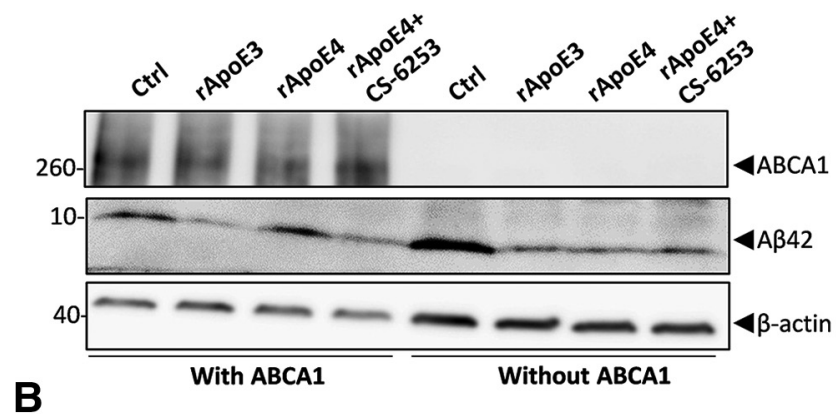

B

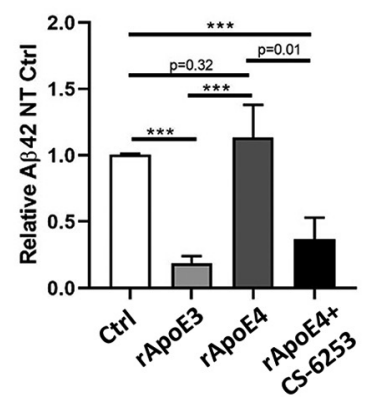

C

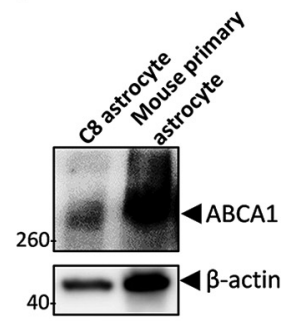

$\mathbf{D}$

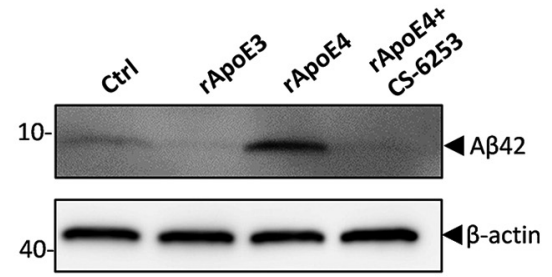

$\mathbf{E}$

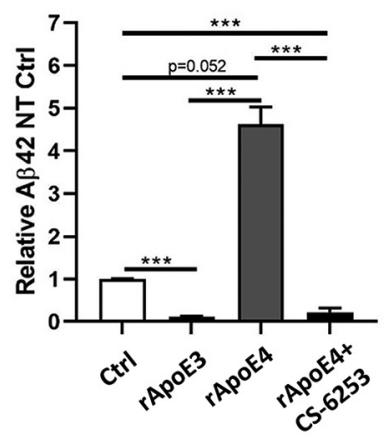

Figure 9. Effect of CS-6253 on ABCA1-mediated A $\beta$ degradation. $A$, BHK cells with or without $A B C A 1$ expression were treated with $A \beta 42(2 \mu \mathrm{g} / \mathrm{ml})$ plus vehicle, rApoE3 $(0.2 \mu \mathrm{m})$, rApoE4 $(0.2 \mu \mathrm{M})$ with or without CS-6253 (1 $\mu \mathrm{M})$ for $24 \mathrm{~h}$. After washing, cells were lysed with RIPA and immunoblotted for measuring $A \beta 42$ protein levels. $B$, Densitometric quantification of Western blot shown in $A$ from three independent experiments. C, ABCA1 expression in $(8$ and wild primary mouse astrocytes (control) was detected by Western blot. D, C 8 astrocytes were treated with $A \beta 42$ ( 2 $\mu \mathrm{g} / \mathrm{ml})$ plus vehicle, rApoE3 $(0.2 \mu \mathrm{M})$, or rApoE4 $(0.2 \mu \mathrm{m})$ with or without CS-6253 $(1 \mu \mathrm{m})$ for $24 \mathrm{~h}$. After washing, cells were lysed with RIPA and immunoblotted for A $\beta$ levels. E, Densitometric quantification of Western blot shown in $\boldsymbol{D}$ from three independent experiments. ${ }^{* *} p<0.001$.

A

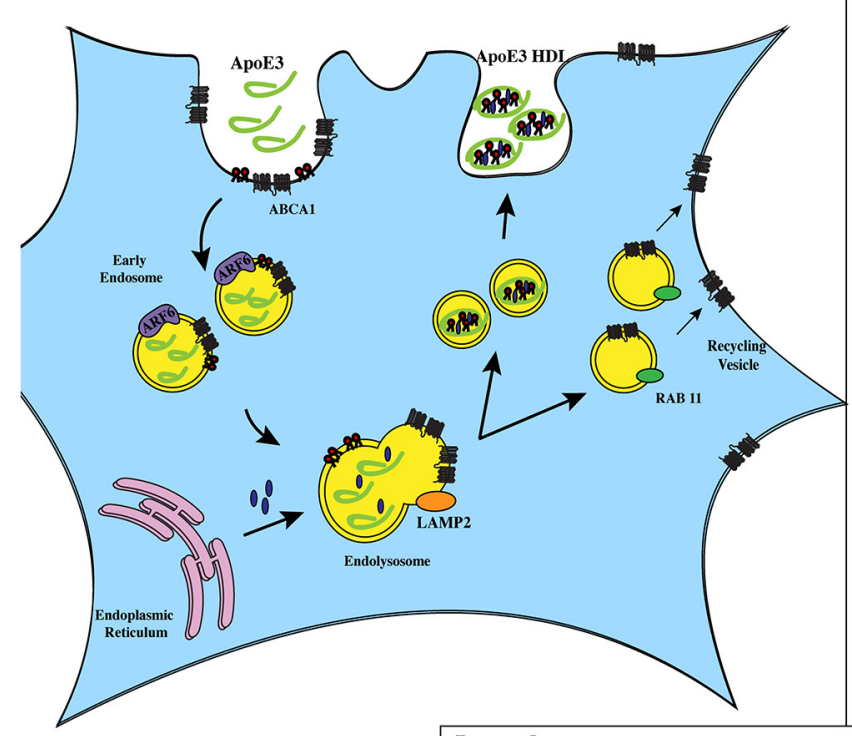

Legend:
B

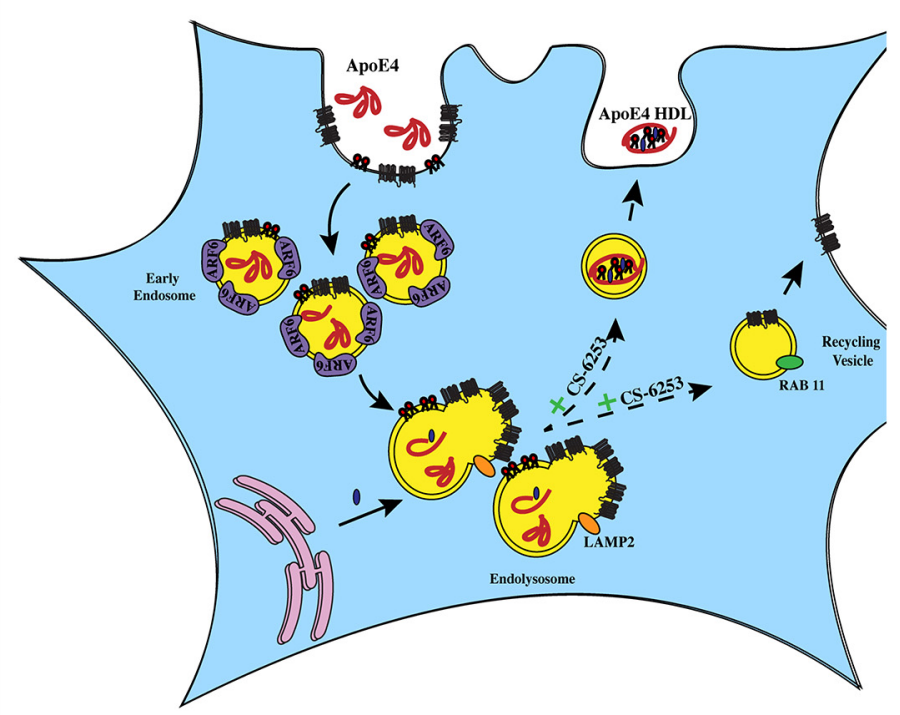

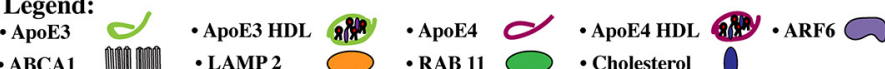

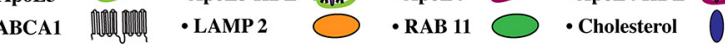

Figure 10. Illustration showing the interaction of ApoE isoforms with $A B C A 1$. $A$, The interaction of ApoE with ABCA1 favors lipidation of ApoE to the form ApoE HDL. $B$, ApoE4 is prone to forming protein aggregates and activates ARF6 that in turn decreases ABCA1 recycling; lowering ABCA1-mediated lipidation of ApoE. CS-6253 promotes ABCA1 recycling to the plasma membrane and favors ApoE lipidation, counteracting the effects of ApoE4.

moting hypolipidated and aggregated ApoE. In addition enhanced ApoE lipidation may prevent adverse effects of ApoE hypolipidation on neurodegeneration caused by insufficient cholesterol supply to neurons (Vitali et al., 2014). Therefore, tar- geting brain $\mathrm{ABCA} 1$ activity presents a promising strategy to mitigate an ApoE4-driven aggregation pathology.

Endosomal dysfunction is an early event in carriers of the APOE4 allele appearing in human brains decades before the onset 
of AD symptoms, and is also observed in ApoE4-TR mouse brain sections (Cataldo et al., 2000; Nuriel et al., 2017). Lipid-poor, aggregated ApoE4 in the acidic endosomal compartment (Morrow et al., 2002) provides a possible mechanism for the endosomal congestion observed in ApoE4. The greater propensity of lipid-poor ApoE4 to aggregate compared with ApoE3 is based on its amino acid sequence and reduced conformational stability of its N-terminal domain (Hatters et al., 2006). Under endosomal acidic conditions, ApoE4 protein forms a molten globule (Morrow et al., 2002), which are protein folding intermediates where the hydrophobic core of the protein is exposed. This associates with an increase in the quantity of ApoE $\beta$ sheets favoring the formation of ApoE4 protein aggregates. One consequence of this increased aggregation is impaired recycling of ApoE4, leading to greater intracellular accumulation compared with ApoE3 (Weisgraber et al., 1982; Heeren et al., 2004). The impaired recycling of the ApoE in endosomes affects multiple cellular pathways of critical relevance to $\mathrm{AD}$ pathology. For example, ApoE4 aggregates with the insulin receptor affecting neuronal glucose uptake (Zhao et al., 2017), with LRP8 and the glutamate receptors (Chen et al., 2010; Xian et al., 2018) affecting synaptic functions, and with LRP-1 affecting $A \beta$ degradation (Prasad and Rao, 2018). Extracellularly, ApoE4 aggregates promote $\mathrm{A} \beta$ oligomerization (Youmans et al., 2012; Tai et al., 2013). Selective removal of these aggregates by the HAE-4 antibody prevented insoluble amyloid fibril accumulation in APP/PS1-21/ApoE4 mice, without altering total ApoE levels in the brain or plasma (Liao et al., 2018).

The major mechanisms of ABCA1 trafficking include clathrindependent pathway, caveolae-dependent pathway, and 2 clathrinindependent pathways: Cdc42 and ARF6-dependent (Mukhamedova et al., 2016). Among the clathrin-independent pathways, ARF6 appears to direct $\mathrm{ABCA} 1$ to late endosomes. We observed greater protein expression of ARF6 in primary ApoE4 astrocytes compared with ApoE3 astrocytes. Reducing ARF6 protein in ApoE4 astrocytes enhanced ABCA1-mediated cholesterol efflux. This finding is consistent with a past study in macrophages and in BHK cells where reducing ARF6 protein expression by siRNA was associated with an increased trafficking of ABCA1 to the plasma membrane, and an increase in cholesterol efflux (Mukhamedova et al., 2016). A likely explanation for the increased ARF6 protein expression in ApoE4 is an interaction among aggregated ApoE4, ARF6 and Rab35, a protein downregulated in young ApoE4-TR mouse brains (Peng et al., 2019). Rab35 is essential for inactivation of ARF6 (Chaineau et al., 2013). Aggregated ApoE4 could potentially downregulate Rab35, indirectly increasing levels of ARF6, as observed here.

Binding of ABCA1 with $\alpha$-helical proteins such as the $\mathrm{C}$ terminus of ApoA-I or ApoE is known to enhance the stability of ABCA1 by limiting its degradation (Lu et al., 2008). CS-6253 is an $\alpha$-helical peptide derived from ApoE's C-terminal lipid-binding segment. It has a greater binding affinity to ABCA1 than ApoE (Hafiane et al., 2015), promoting ABCA1 recycling to the plasma membrane, and resulting in enhanced cholesterol efflux. In our study, treatment with CS-6253 decreased the amount of ApoE4 and ABCA1 in aggregates in hippocampal homogenates of ApoE4-TR mice. This may provide an explanation for the previously observed neuroprotective effects of CS-6253 in vivo: decreased intraneuronal $\mathrm{A} \beta$ and tau, improved synaptic markers and cognitive deficits in ApoE4-TR mice (Boehm-Cagan et al., 2016). There are at least two potential mechanisms for how inducing ABCA1 activity may decrease ApoE aggregation. First, phospholipid and cholesterol transfer to ApoE by increased ABCA1 activity may decrease the availability of lipid-poor ApoE4 molecules that are aggregation prone. Alternatively, formation of brain HDL from lipidating CS-6253 by ABCA1 may directly solubilize lipid-poor ApoE protein aggregates into HDL particles.

We previously demonstrated that CSF of individuals with cognitive impairment and $\mathrm{AD}$ had less ABCA1 cholesterol efflux activity ex vivo compared with cognitively normal individuals (Yassine et al., 2016). Here, we extend this observation to nondemented APOE4 homozygotes compared with noncarriers. Our findings indicate that lower ABCA1 cholesterol efflux activity with APOE4 precedes the onset of dementia. This agrees with neuropathological observations of enlarged endosomes (trapping ApoE complexed with other proteins such as ABCA1) appearing in the brains of APOE4 carriers decades before the onset of cognitive decline (Cataldo et al., 2000). ABCA1-mediated cholesterol efflux function of CSF can therefore serve as a biomarker for strategies focused on $\mathrm{AD}$ prevention. We found that lower ABCA1-mediated cholesterol efflux of CSF can be rescued ex vivo by treatment with CS-6253. An interesting observation was that $A P O E \varepsilon 4 / \varepsilon 4$ CSF was the least responsive to enhancing ABCA1 activity while $A P O E \varepsilon 3 / \varepsilon 4$ was the best. Further studies are needed to explain this observation.

This study has several areas of strengths and some limitations. We tested and confirmed our findings on ABCA1 and ApoE aggregation using several independent models (multiple cell lines, with endogenous ApoE production or after the addition of rApoE isoforms) and used animal brains and human CSF to demonstrate the clinical relevance of our findings. Some of the limitations of this study include that we only studied male mice. The sample size of CSF from cognitively normal APOE $\varepsilon 4 / \varepsilon 4$ homozygotes was low $(n=3)$, but this genotype is present in low population frequency. Future studies are required to identify if there is a sex-difference in the ABCA1-ApoE (patho-)physiology.

In conclusion, this study identifies an important crosstalk between ApoE lipidation and aggregation dependent on ABCA1 function. Because ApoE aggregation associates with dysfunction in several cellular pathways ( $\mathrm{A}$ degradation, insulin signaling, and synaptic functions), our study underscores the importance of stabilizing ABCA1 activity in reducing ApoE4-driven aggregation pathology.

\section{References}

Boehm-Cagan A, Bar R, Liraz O, Bielicki JK, Johansson JO, Michaelson DM (2016) ABCA1 agonist reverses the ApoE4-driven cognitive and brain pathologies. J Alzheimers Dis 54:1219-1233.

Cataldo AM, Peterhoff CM, Troncoso JC, Gomez-Isla T, Hyman BT, Nixon RA (2000) Endocytic pathway abnormalities precede amyloid beta deposition in sporadic Alzheimer's disease and down syndrome: differential effects of APOE genotype and presenilin mutations. Am J Pathol 157:277286.

Chaineau M, Ioannou MS, McPherson PS (2013) Rab35: GEFs, GAPs and effectors. Traffic 14:1109-1117.

Chen Y, Durakoglugil MS, Xian X, Herz J (2010) ApoE4 reduces glutamate receptor function and synaptic plasticity by selectively impairing ApoE receptor recycling. Proc Natl Acad Sci U S A 107:12011-12016.

Chernick D, Ortiz-Valle S, Jeong A, Swaminathan SK, Kandimalla KK, Rebeck GW, Li L (2018) High-density lipoprotein mimetic peptide 4F mitigates amyloid-beta-induced inhibition of apolipoprotein E secretion and lipidation in primary astrocytes and microglia. J Neurochem 147:647-662.

Hafiane A, Bielicki JK, Johansson JO, Genest J (2015) Novel Apo E-derived ABCA1 agonist peptide (CS-6253) promotes reverse cholesterol transport and induces formation of prebeta-1 HDL in vitro. PLoS One 10:e131997.

Hatters DM, Zhong N, Rutenber E, Weisgraber KH (2006) Amino-terminal domain stability mediates apolipoprotein $\mathrm{E}$ aggregation into neurotoxic fibrils. J Mol Biol 361:932-944.

Heeren J, Grewal T, Laatsch A, Becker N, Rinninger F, Rye KA, Beisiegel U (2004) Impaired recycling of apolipoprotein E4 is associated with intracellular cholesterol accumulation. J Biol Chem 279:55483-55492. 
Heinsinger NM, Gachechiladze MA, Rebeck GW (2016) Apolipoprotein E genotype affects size of ApoE complexes in cerebrospinal fluid. J Neuropathol Exp Neurol 75:918-924.

Hirsch-Reinshagen V, Zhou S, Burgess BL, Bernier L, McIsaac SA, Chan JY, Tansley GH, Cohn JS, Hayden MR, Wellington CL (2004) Deficiency of ABCA1 impairs apolipoprotein E metabolism in brain. J Biol Chem 279:41197-41207.

Hu J, Liu CC, Chen XF, Zhang YW, Xu H, Bu G (2015) Opposing effects of viral mediated brain expression of apolipoprotein E2 (apoE2) and apoE4 on apoE lipidation and Abeta metabolism in apoE4-targeted replacement mice. Mol Neurodegener 10:6.

Hubin E, Verghese PB, van Nuland N, Broersen K (2019) Apolipoprotein E associated with reconstituted high-density lipoprotein-like particles is protected from aggregation. FEBS Lett 593:1144-1153.

Jiang Q, Lee CY, Mandrekar S, Wilkinson B, Cramer P, Zelcer N, Mann K, Lamb B, Willson TM, Collins JL, Richardson JC, Smith JD, Comery TA, Riddell D, Holtzman DM, Tontonoz P, Landreth GE (2008) ApoE promotes the proteolytic degradation of abeta. Neuron 58:681-693.

Jiang YJ, Lu B, Kim P, Elias PM, Feingold KR (2006) Regulation of ABCA1 expression in human keratinocytes and murine epidermis. J Lipid Res 47:2248-2258.

Koldamova R, Staufenbiel M, Lefterov I (2005) Lack of ABCA1 considerably decreases brain ApoE level and increases amyloid deposition in APP23 mice. J Biol Chem 280:43224-43235.

Lee CY, Tse W, Smith JD, Landreth GE (2012) Apolipoprotein E promotes $\beta$-amyloid trafficking and degradation by modulating microglial cholesterol levels. J Biol Chem 287:2032-2044.

Liao F, Li A, Xiong M, Bien-Ly N, Jiang H, Zhang Y, Finn MB, Hoyle R, Keyser J, Lefton KB, Robinson GO, Serrano JR, Silverman AP, Guo JL, Getz J, Henne K, Leyns CE, Gallardo G, Ulrich JD, Sullivan PM, et al. (2018) Targeting of nonlipidated, aggregated apoE with antibodies inhibits amyloid accumulation. J Clin Invest 128:2144-2155.

Lu R, Arakawa R, Ito-Osumi C, Iwamoto N, Yokoyama S (2008) ApoA-I facilitates ABCA1 recycle/accumulation to cell surface by inhibiting its intracellular degradation and increases HDL generation. Arterioscler Thromb Vasc Biol 28:1820-1824.

Mandrekar-Colucci S, Landreth GE (2011) Nuclear receptors as therapeutic targets for Alzheimer's disease. Expert Opin Ther Targets 15:1085-1097.

Marchi C, Adorni MP, Caffarra P, Ronda N, Spallazzi M, Barocco F, Galimberti D, Bernini F, Zimetti F (2019) ABCA1- and ABCG1-mediated cholesterol efflux capacity of cerebrospinal fluid is impaired in Alzheimer's disease. J Lipid Res 60:1449-1456.

Morikawa M, Fryer JD, Sullivan PM, Christopher EA, Wahrle SE, DeMattos RB, O'Dell MA, Fagan AM, Lashuel HA, Walz T, Asai K, Holtzman DM (2005) Production and characterization of astrocyte-derived human apolipoprotein $\mathrm{E}$ isoforms from immortalized astrocytes and their interactions with amyloid-beta. Neurobiol Dis 19:66-76.

Morrow JA, Hatters DM, Lu B, Hochtl P, Oberg KA, Rupp B, Weisgraber KH (2002) Apolipoprotein E4 forms a molten globule. A potential basis for its association with disease. J Biol Chem 277:50380-50385.

Mukhamedova N, Hoang A, Cui HL, Carmichael I, Fu Y, Bukrinsky M, Sviridov D (2016) Small GTPase ARF6 regulates endocytic pathway leading to degradation of ATP-binding cassette transporter A1. Arterioscler Thromb Vasc Biol 36:2292-2303.

Nordestgaard LT, Tybjærg-Hansen A, Nordestgaard BG, Frikke-Schmidt R (2015) Loss-of-function mutation in ABCA1 and risk of Alzheimer's disease and cerebrovascular disease. Alzheimers Dement 11:1430-1438.

Nuriel T, Peng KY, Ashok A, Dillman AA, Figueroa HY, Apuzzo J, Ambat J,
Levy E, Cookson MR, Mathews PM, Duff KE (2017) The endosomallysosomal pathway is dysregulated by APOE4 expression in vivo. Front Neurosci 11:702.

Peng KY, Goulbourne CN, Pérez-González R, Morales-Corraliza J, Alldred MJ, Mathews PM, Saito M, Saito M, Ginsberg SD, Mathews PM, Levy E (2019) Apolipoprotein E4 genotype compromises brain exosome production. Brain 142:163-175.

Prasad H, Rao R (2018) Amyloid clearance defect in ApoE4 astrocytes is reversed by epigenetic correction of endosomal pH. Proc Natl Acad Sci U S A 115:E6640-E6649.

Raulin AC, Kraft L, Al-Hilaly YK, Xue WF, McGeehan JE, Atack JR, Serpell L (2019) The molecular basis for apolipoprotein E4 as the major risk factor for late-onset Alzheimer's disease. J Mol Biol 431:2248-2265.

Simonovitch S, Schmukler E, Bespalko A, Iram T, Frenkel D, Holtzman DM, Masliah E, Michaelson DM, Pinkas-Kramarski R (2016) Impaired autophagy in APOE4 astrocytes. J Alzheimers Dis 51:915-927.

Sullivan PM, Mezdour H, Aratani Y, Knouff C, Najib J, Reddick RL, Quarfordt SH, Maeda N (1997) Targeted replacement of the mouse apolipoprotein E gene with the common human APOE3 allele enhances diet-induced hypercholesterolemia and atherosclerosis. J Biol Chem 272:17972-17980.

Tai LM, Bilousova T, Jungbauer L, Roeske SK, Youmans KL, Yu C, Poon WW, Cornwell LB, Miller CA, Vinters HV, Van Eldik LJ, Fardo DW, Estus S, Bu G, Gylys KH, Ladu MJ (2013) Levels of soluble apolipoprotein E/amyloid-beta (Abeta) complex are reduced and oligomeric abeta increased with APOE4 and alzheimer disease in a transgenic mouse model and human samples. J Biol Chem 288:5914-5926.

Vance JE, Hayashi H (2010) Formation and function of apolipoprotein E-containing lipoproteins in the nervous system. Biochem Biophys Acta 1801:806-818.

Vitali C, Wellington CL, Calabresi L (2014) HDL and cholesterol handling in the brain. Cardiovasc Res 103:405-413.

Wahrle SE, Jiang H, Parsadanian M, Legleiter J, Han X, Fryer JD, Kowalewski $\mathrm{T}$, Holtzman DM (2004) ABCA1 is required for normal central nervous system ApoE levels and for lipidation of astrocyte-secreted apoE. J Biol Chem 279:40987-40993.

Wahrle SE, Jiang H, Parsadanian M, Kim J, Li A, Knoten A, Jain S, HirschReinshagen V, Wellington CL, Bales KR, Paul SM, Holtzman DM (2008) Overexpression of ABCA1 reduces amyloid deposition in the PDAPP mouse model of alzheimer disease. J Clin Invest 118:671-682.

Weisgraber KH, Innerarity TL, Mahley RW (1982) Abnormal lipoprotein receptor-binding activity of the human $\mathrm{E}$ apoprotein due to cysteinearginine interchange at a single site. J Biol Chem 257:2518-2521.

Xian X, Pohlkamp T, Durakoglugil MS, Wong CH, Beck JK, Lane-Donovan C, Plattner F, Herz J (2018) Reversal of ApoE4-induced recycling block as a novel prevention approach for Alzheimer's disease. eLife 7:e40048.

Yassine HN, Feng Q, Chiang J, Petrosspour LM, Fonteh AN, Chui HC, Harrington MG (2016) ABCA1-mediated cholesterol efflux capacity to cerebrospinal fluid is reduced in patients with mild cognitive impairment and Alzheimer's disease. J Am Heart Assoc 5:e002886.

Youmans KL, Tai LM, Nwabuisi-Heath E, Jungbauer L, Kanekiyo T, Gan M, Kim J, Eimer WA, Estus S, Rebeck GW, Weeber EJ, Bu G, Yu C, Ladu MJ (2012) APOE4-specific changes in abeta accumulation in a new transgenic mouse model of Alzheimer disease. J Biol Chem 287:41774-41786.

Zhao N, Liu CC, Van Ingelgom AJ, Martens YA, Linares C, Knight JA, Painter MM, Sullivan PM, Bu G (2017) Apolipoprotein E4 impairs neuronal insulin signaling by trapping insulin receptor in the endosomes. Neuron 96:115-129.e5. 